UNIVERSIDADE DE SÃO PAULO

FACULDADE DE MEDICINA DE RIBEIRÃO PRETO

DEPARTAMENTO DE ORTOPEDIA E ANESTESIOLOGIA

CARLOS ALEXANDRE DE FREITAS TRINDADE

AVALIAÇÃO DO EFEITO ANTINOCICEPTIVO DA ABLAÇÃO NEUROPÁTICA E AUTONÔMICA POR RADIOFREQUÊNCIA EM PACIENTES PORTADORES DE DOR CRÔNICA SÍNDROME DOLOROSA COMPLEXA REGIONAL DO TIPO-I: AVALIAÇÃO DE PACIENTES COM DOR LOMBAR CRÔNICA

RIBEIRÃO PRETO - SP 


\title{
AVALIAÇÃO DO EFEITO ANTINOCICEPTIVO DA ABLAÇÃO NEUROPÁTICA E AUTONÔMICA POR RADIOFREQUÊNCIA EM PACIENTES PORTADORES DE DOR CRÔNICA SÍNDROME DOLOROSA COMPLEXA REGIONAL DO TIPO-I: AVALIAÇÃO DE PACIENTES COM DOR LOMBAR CRÔNICA
}

\author{
Versão Original
}

Dissertação de Mestrado apresentada ao Programa de Pós-Graduação em Ciências da Saúde Aplicadas ao Aparelho Locomotor da Faculdade de Medicina de Ribeirão Preto - FMRP/USP, como requisito parcial à obtenção do título de Mestre em Ciências.

Orientadora: Prof ${ }^{\mathrm{a}}$. Gabriela Rocha Lauretti

RIBEIRÃO PRETO - SP 


\section{Ficha Catalográfica}

Trindade, Carlos Alexandre de Freitas

Avaliação do efeito antinociceptivo da ablação neuropática e autonômica por radiofrequência em pacientes portadores de dor crônica Síndrome Dolorosa Complexa Regional do Tipo-I: Avaliação de pacientes com dor lombar crônica. Ribeirão Preto, 2020.

63 p.: il.; $30 \mathrm{~cm}$.

Dissertação de Mestrado apresentada ao Programa de Pós Graduação em Ciências da Saúde Aplicadas ao Aparelho Locomotor da Faculdade de Medicina de Ribeirão Preto/USP.

Orientadora: Lauretti, Gabriela Rocha.

1. Dor lombar crônica. 2. Tratamento da dor. 3. Síndrome dolorosa complexa regional tipo 1. 4. Bloqueio neuropático. 5. Radiofrequência 
Dedico este estudo aos meus filhos, Rafael e Henrique, que eles entendam, no futuro, que a educação é capaz de mudar pessoas e sociedades para melhor. Dedico à minha esposa Eliza, que me apoia em todos os meu planos e projetos, mesmo dos quais não participa diretamente. Dedico aos meus pais, Carlos e Marli, que se doaram ao longo da vida em prol da minha educação. Dedico ao meu irmão e melhor amigo, Luís, que participa em todas as minhas decisões profissionais, com conselhos simples e serenos, talvez sem acreditar no grau de importância em minha vida 


\section{AGRADECIMENTOS}

Agraço à Professora $\operatorname{Dr}^{\mathrm{a}}$ Gabriela Lauretti, por acreditar que eu seria capaz de atendê-la à altura, abrindo as portas do seu serviço do CET-DOR-HC-USP-RP e me confiando um projeto ligado a seu nome. Convivendo com ela, entendi que enxergar além do problema, e proporcionar acolhimento do paciente são partes fundamentais do tratamento. A você, minha admiração como profissional e como pessoa.

Agradeço aos funcionários do CET-DOR-HC-USP-RP por participarem direta ou indiretamente do projeto, com o carinho habitual com que tratam os pacientes.

Agradeço aos pacientes, pela confiança em nosso trabalho e pela disponibilidade em participar do estudo. A soma dos nossos esforços poderá afetar positivamente a vida de muitos outros.

Agradeço ao programa de pós-graduação: Ciências da Saúde Aplicadas ao Aparelho Locomotor, da FMRP-USP, extensivo a todos os funcionários, por acreditarem no meu projeto e na minha capacidade de realizá-lo, apesar das dificuldades que encontrei durante a caminhada.

Agradecimentos extensivos à Coordenação de Aperfeiçoamento de Pessoal de Nível Superior - CAPES. 


\section{RESUMO}

Trindade CAF. Avaliação do efeito antinociceptivo da ablação neuropática e autonômica por radiofrequência em pacientes portadores de dor crônica Síndrome Dolorosa Complexa Regional do Tipo-I: avaliação de pacientes com dor lombar crônica [dissertação]. Ribeirão Preto: Universidade de São Paulo, Faculdade de Medicina de Ribeirão Preto; 2020.

A Sindrome Dolorosa Complexa Regional do tipo I (SDCR-I) é uma doença complexa com inúmeras propostas terapêuticas para a qual não existe um protocolo padrão de tratamento. $\mathrm{Na}$ Clínica para o Tratamento da Dor- Hospital das Clínicas- Faculdade de Medicina de Ribeirão Preto - Universidade de São Paulo (CTDor- HC- FMRP-USP) bloqueios autonômicos associados ao bloqueio neuropático são realizados rotineiramente uma vez por semana durante uma média de quatro semanas consecutivas no tratamento da SDCR-I. A ablação combinada dos componentes neuropático e autonômico por radiofrequência (RF) é uma técnica minimamente invasiva (através do aumento de temperatura programada) que permite a lesão limitada unicamente ao tecido escolhido. Outra grande vantagem é durabilidade mais prolongada do efeito dessa técnica. Este estudo visa avaliar o efeito antinociceptivo da ablação por RF de tecido neuropático e do gânglio simpático em pacientes portadores de dor crônica com componente misto neuropático e autonômico, além de sua efetividade, durabilidade e custo financeiro, comparada à técnica convencional de quatro bloqueios, durante o período de 12 meses. O estudo foi prospectivo, aleatório, duplamente-encoberto, sendo que cada paciente atuou como seu próprio controle (avaliação Crossover). Vinte e quatro pacientes participaram da avaliação final. No Grupo 1 , no qual os pacientes foram submetidos à sequência de quatro bloqueios semanais, a média do tempo de analgesia foi 5,5 $( \pm 1,47)$ meses, significativamente menor do que a média de tempo de analgesia após a realização de RF nos mesmos pacientes, $15,5( \pm 2,34)$ meses $(p<0,001)$. Durante o período no qual a analgesia foi considerada adequada e inadequada o consumo de analgésicos de resgate (Tramadol $50 \mathrm{mg}$ ) foi semelhante, porém foi observada melhor qualidade do sono e da capacidade de realizar atividades rotineiras no período de analgesia adequado ( $p<0,001$ e $p<0,05$, respectivamente). Foi observada uma economia de $24,94 \%$ por paciente no primeiro ano de tratamento quando a técnica de RF foi utilizada em comparação a técnica convencional de quatro bloqueios. Essa porcentagem aumentou progressivamente chegando a 37,03\% em 30 anos. Sendo assim, a técnica de RF dos mesmos níveis para ablação simpática e modulação do GRD (L3-L4-L5) foi econômica e resultou em tempo de analgesia significativamente superior quando comparada à sequência tradicional de quatro bloqueios. Os dados sugerem, portanto, que o tratamento da sensibilização central à dor deve ser considerado nessa população do estudo.

Palavras-chave: Dor lombar crônica. Tratamento da dor. Síndrome dolorosa complexa regional tipo 1. Bloqueio neuropático. Radiofrequência. 


\begin{abstract}
Trindade CAF. Evaluation of the antinociceptive effect of neuropathic and autonomic radiofrequency ablation in patients with chronic pain Complex regional pain syndrome type I: Evaluation of patients with chronic lumbar pain [thesis]. Ribeirão Preto: Universidade de São Paulo, Faculdade de Medicina de Ribeirão Preto; 2020.

Complex regional pain syndrome type I (SDCR-I) is a complex disease with numerous therapeutic proposals for which there is no standard treatment protocol. At the Clínica para o Tratamento da Dor- Hospital das Clínicas- Faculdade de Medicina de Ribeirão Preto Universidade de São Paulo (CTDor- HC- FMRP-USP) autonomic blocks associated with neuropathic block are routinely performed once a week for an average of four consecutive weeks in the treatment of SDCR-I. The combined ablation of the neuropathic and autonomic components by radiofrequency (RF) is a minimally invasive technique (through the programmed temperature increase) that allows the lesion limited only to the chosen tissue. Another great advantage is the longer durability of the effect of this technique. This study aims to evaluate the antinociceptive effect of RF ablation of neuropathic tissue and sympathetic ganglion in patients with chronic pain with a mixed neuropathic and autonomic component, in addition to its effectiveness, durability and financial cost, compared to the conventional fourblock technique, during the 12-month period. The study was prospective, random, double-blind, with each patient acting as his own control (Crossover evaluation). Twenty-four patients participated in the final evaluation. In Group 1, in which patients underwent a sequence of four weekly blocks, the average analgesia time was $5.5( \pm 1.47)$ months, significantly less than the average analgesia time after performing RF in the same patients, $15.5( \pm 2.34)$ months $(p<$ 0.001). During the period in which analgesia was considered adequate and inadequate, the use of rescue analgesics (Tramadol $50 \mathrm{mg}$ ) was similar, but better sleep quality and the ability to perform routine activities in the appropriate analgesia period were observed $(\mathrm{p}<0.001$ and $\mathrm{p}<$ 0.05 , respectively). Savings of $18,06 \%$ per patient were observed in the first year of treatment when the RF technique was used in comparison to the conventional four-block technique. This percentage increased progressively, reaching $30,15 \%$ in 30 years. Thus, the RF technique of the same levels for sympathetic ablation and GRD modulation (L3-L4-L5) was economical and resulted in significantly longer analgesia time when compared to the traditional sequence of four blocks. The data therefore suggest that the treatment of central pain sensitization should be considered in this study population.
\end{abstract}

Keywords: Chronic low back pain. Pain treatment. Complex regional pain syndrome type 1 . Neuropathic block. Radiofrequency. 


\section{LISTA DE ABREVIATURAS E SIGLAS}

CGRP Peptídeo relacionado ao gene da calcitonina

$\mathrm{cm}$

Centímetros

CTDor- HC- FMRP-USP Clínica para o Tratamento da Dor- Hospital das Clínicas, da Faculdade de Medicina de Ribeirão Preto, Universidade de São Paulo

DRG

ENCap

END

ENSono

$\mathrm{Hz}$

IASP

IL

$\mathrm{Kg}$

$\operatorname{mcg}$

mg

$\mathrm{ml}$

$\mathrm{mm}$

$\mathrm{mV}$

$\mathrm{RF}$

SDCR

SF $0,9 \%$

SUS

TNF- $\alpha$

$\mathrm{V}$
Gânglio de raiz dorsal

Escala Numérica de Capacidade

Escala Numérica de Dor

Escala Numérica de Sono

Hertz

International Association for the Study of Pain

Interleucina

Quilogramas

Microgramas

Miligramas

Mililitros

Milímetros

Milivolts

Radiofrequência

Síndrome de dor complexa regional

Soro fisiológico a $0,9 \%$

Sistema Único de Saúde

Fator de necrose tumoral alfa

Volts 


\section{LISTA DE FIGURAS}

Figura 1 - Configuração da lesão térmica na ponta da agulha de radiofrequência. A lesão apresenta-se como uma pera com a base proximal na ponta ativa, diâmetro aproximado de lesão térmica $3 \mathrm{~mm}$ 18

Figura 2 - Fluxograma inicial da divisão dos grupos experimentais e do estudo no tempo. Escala Numérica de Dor (END): 0-10 cm.

Figura 3 - Agulha posicionada no espaço peridural sacral, visão de perfil, após administração de $0,5 \mathrm{ml}$ de contraste não-iodado Omnipaque ${ }^{\circledR}$.

Figura 4 - Bloqueio simpático lombar L3, visão oblíqua. .30

Figura 5 - Bloqueio gânglio dorsal lombar L4, L5, visão oblíqua. 31

Figura 6 - Bloqueio gânglio dorsal lombar L4, L5, visão de perfil. 31

Figura 7 - Posicionamento percutâneo das agulhas de radiofrequência na região lombar anterior aos corpos vertebrais de L3, L4 e L5, visando os gânglios simpáticos lombares correspondentes.

Figura 8 - Fluxograma final do estudo. .35

Figura 9 - Tempo de analgesia adequado $($ END $<4)$ em meses após sequência de 4 bloqueios e após RF avaliados em 24 pacientes, sendo que cada paciente atuou como seu próprio controle.

Figura 10 - Qualidade do sono durante os períodos de analgesia inadequada e adequada. Cada ícone representa um paciente ( $\mathrm{n}=24$ pacientes). As linhas conectam o resultado apresentado por cada paciente no momento em que a analgesia foi considerada inadequada (END $\geq 4$ ) e adequada $(\mathrm{END}<4)$. 
Figura 11 - Capacidade para realização de atividades rotineiras durante os períodos de analgesia inadequada e adequada. Cada ícone representa um paciente ( $\mathrm{n}=24$ pacientes). As linhas conectam o resultado apresentado por cada paciente no momento em que a analgesia foi considerada inadequada $($ END $\geq 4)$ e adequqda $($ END $<4)$.

Figura 12 - Custo anual estimados por pacientes utilizando a técnica de 4 bloqueios ou radiofrequência (RF) com extrapolação para o período de 5 (cinco) anos. A porcentagem (\%) indica a economia por paciente, em cada período, utilizando a RF em relação à técnica de 4 bloqueios.

Figura 13 - Custo anual estimados por pacientes utilizando a técnica de 4 bloqueios ou radiofrequência (RF) com extrapolação para o período de 15 (quinze) anos. A porcentagem (\%) indica a economia por paciente, em cada período, utilizando a RF em relação à técnica de 4 bloqueios. 


\section{LISTA DE QUADROS}

Quadro 1 - Critérios de Budapeste

Quadro 2 - Custo anual de sequência de 4 bloqueios (Grupo 1) por paciente portador da SDCRI. .41

Quadro 3 - Custo anual de bloqueio teste seguido de ablação por RF (Grupo 2) por paciente portador de SDCR-I. . 


\section{LISTA DE TABELAS}

Tabela 1 - Dados demográficos dos pacientes diagnosticados com SDCR-I incluídos no estudo, segundo idade (anos), peso $(\mathrm{Kg})$, altura $(\mathrm{cm})$, tempo de dor (meses), religião, gênero, etnia e uso de medicamentos. 36

Tabela 2 - Avaliação da dor em pacientes portadores de SDCR-I, submetidos à sequência de quatro bloqueios semanais (Grupo 1) ou a ablação por radiofrequência (Grupo 2)

Tabela 3 - Avaliação do consumo de analgésicos de resgate (Tramadol) durante os períodos de analgesia adequada e inadequada em pacientes portadores de SDCR-I.

Tabela 4 - Avaliação da qualidade do sono e da capacidade de realizar atividades rotineiras em pacientes portadores de SDCR-I, submetidos à sequência de quatro bloqueios semanais (Grupo 1) ou de ablação por radiofrequência (Grupo 2) durante os períodos de analgesia adequada e inadequada.

Tabela 5 - Custo e economia anual por paciente considerando os diferentes esquemas de tratamento, 4 bloqueios ou radiofrequência (RF) no período de 1 ano, extrapolado para demais anos de tratamento. 


\section{SUMÁRIO}

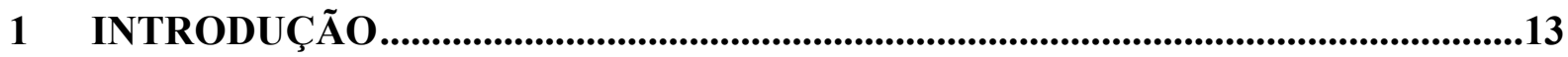

1.1 Sinais e sintomas da SDRC ................................................................................14

1.2 Critérios diagnósticos da SDRC ………….....................................................................14

1.3 Tratamento clínico da SDCR ...........................................................................................15

1.4 Tratamento intervencionista da SDCR........................................................................16

1.4.1 Radiofrequência …………………………………………………………………....17

1.4.1.1 Radiofrequência: mecanismos de ação ………………………………………...17

1.4.1.2 Radiofrequência ablativa: lesão por corrente iônica ..........................................18

1.4.1.3 Radiofrequência pulsada ...........................................................................20

2 JUSTIFICATIVA _...............................................................................................................22

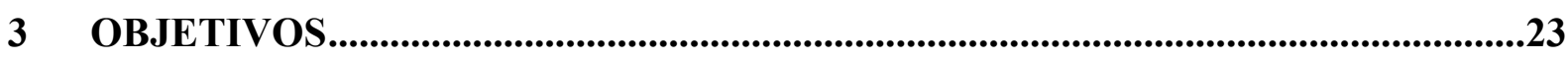

3.1 Objetivo Geral ..............................................................................................................23

3.2 Objetivos específicos ...............................................................................................23

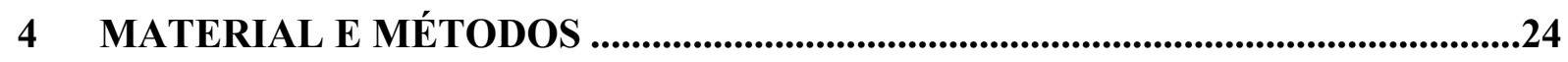

4.2 População de estudo ........................................................................................................24

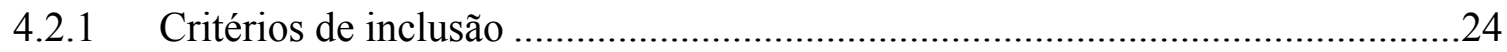

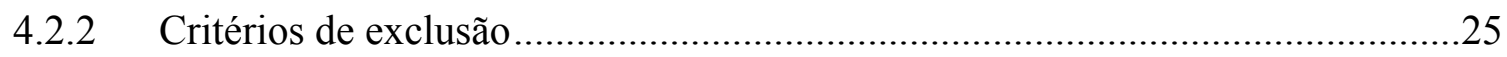

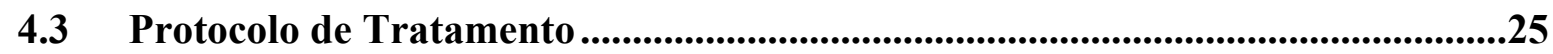

4.3.1 Delineamento experimental ......................................................................26

4.4 Fármacos utilizados......................................................................................................27

4.5 Téenicas de bloqueios.........................................................................................................28

4.6 Bloqueio peridural por via sacral ..................................................................................28

4.6.1 Bloqueio autônomo simpático lombar ..............................................................29

4.6.2 Bloqueio do gânglio dorsal transforaminal lombar .............................................30 
4.6.3 Ablação convencional do gânglio simpático lombar de L3, L4 e L5 do lado acometido

4.6.4 Modulação do gânglio dorsal transforaminal .....................................................32

4.7 Análise demográfica da população do estudo.................................................32

4.8 Avaliação da dor ............................................................................................................33

4.9 Avaliação da qualidade de sono e atividades diárias ............................................33

4.10 Avaliação do custo financeiro durante as fases de bloqueio teste e de radiofrequência ......................................................................................................................34

4.11 Avaliação dos efeitos adversos ..............................................................................34

4.12 Análise estatística e determinação do número amostral.........................................34

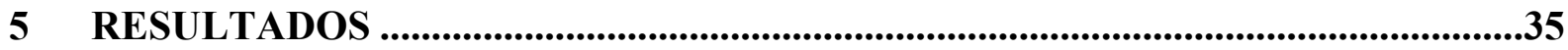

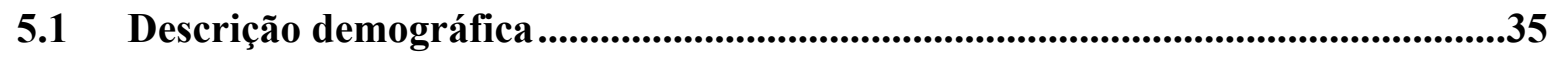

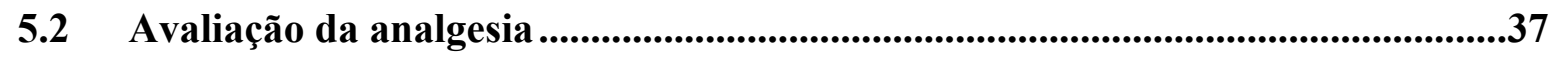

5.3 Avaliação da qualidade de sono e da capacidade para realização de atividades rotineiras diárias ...............................................................................................................38

5.4 Avaliação do custo anual gasto para controle da dor nos pacientes portadores de

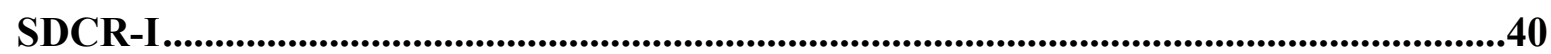

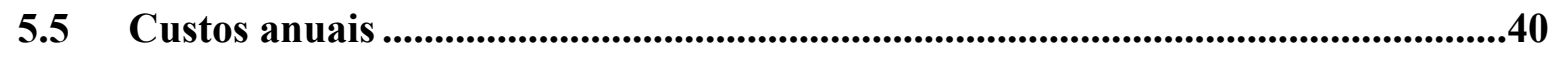

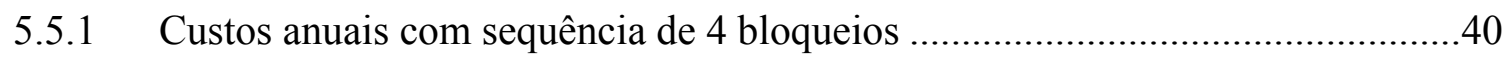

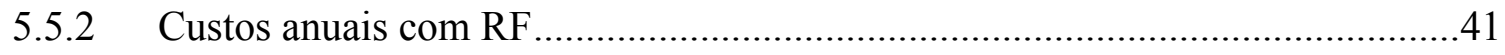

5.5.3 Extrapolação dos custos ao longo dos anos e economia por paciente .................42

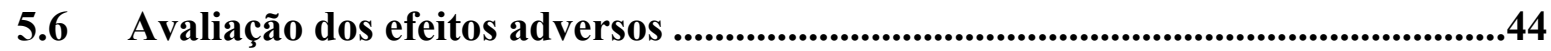

6 DISCUSSÃO

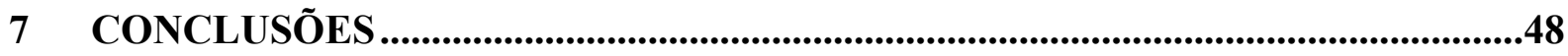

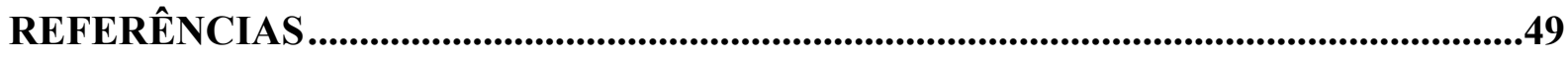

ANEXO - Termo de Consentimento Livre e Esclarecido....................................................60 


\section{INTRODUÇÃO}

A síndrome de dor complexa regional (SDCR) é uma condição neurológica crônica, relacionada a um trauma, com prevalência de aproximadamente 5,4 a 26,2 a cada 100.000 pessoas. (1) Ela se distingue das outras síndromes dolorosas pela presença de disfunções autonômicas e persistência de alterações inflamatórias crônicas. Além disso, a dor não apresenta correspondência dermatomérica com uma área de inervação específica. É uma condição de natureza enigmática e, portanto, de difícil diagnóstico e tratamento, muito provavelmente pela fisiopatologia não ser completamente compreendida. (2,3)

A SDCR pode ser dividida em dois subtipos, baseados na ausência ou presença de uma lesão nervosa: SDCR tipo I e SDRC tipo II, respectivamente. A classificação da SDCR foi realizada pela International Association for the Study of Pain (IASP), e mais recentemente pelo Grupo de Budapest (Critérios de Budapest). (4) Em 2014, a IASP alterou a classificação da dor, sendo que a SDCR-I foi classificada como dor nociplástica e a do tipo II classificada como dor neuropática. Esses critérios foram revisados em 2016 por Kumar e Elavarasi. (5)

Casos de SDCR são descritos desde o século XVI. Os primeiros casos da América do Norte foram descritos em 1864, por Silas Weir Mitchell, que observou um tipo de dor que acometia pacientes vítimas de arma de fogo durante a guerra Civil. (6) Vários estudos tentaram associar a SDCR às alterações genéticas, porém os resultados ainda são inconclusivos em relação à confirmação de predisposição ou causalidade. (7-10)

Estudos recentes demonstraram que a incidência de SDCR é discrepante entre gêneros, sendo o feminino o mais acometido ( $71 \%$ comparado a $29 \%$ no gênero masculino). O membro superior é o mais acometido (70\% dos pacientes) e a SDCR tipo I ocorre mais frequentemente que a SDCR tipo II (88\% e 12\%, respectivamente). (11) Em contrapartida, Kim et al. (12) em um estudo epidemiológico, utilizando dados de 74.000 pacientes obtidos do serviço de seguro de saúde nacional da Coréia do Sul, observaram uma disparidade menor entre homens e mulheres. A década de maior incidência dos sintomas foi entre 70 e 79 anos, significativamente superior quando comparados com os estudos de Sandroni et al. (13), que demonstrou prevalência do início dos sintomas em pacientes com idade média de 46 anos; e com o estudo de Ott e Maihofner (11), no qual a idade média de início dos sintomas foi de 50,1 anos. Por fim, na população coreana, a pelve e os membros inferiores foram mais afetados que os membros superiores. (12) 
A grande variabilidade observada em estudos epidemiológicos da literatura escancara os desafios do diagnóstico da SDCR. Entretanto, tanto a incidência quanto a prevalência da doença variam muito de acordo com os critérios diagnósticos utilizados.

\subsection{Sinais e sintomas da SDRC}

Pacientes com SDRC exibem uma diversa gama de sintomas, incluindo anormalidades sensoriais, disfunções autônomas e motoras durante o desenrolar da doença. (14) Sintomas clássicos incluem dor forte, em queimação, geralmente desproporcionais ao evento desencadeador. A dor, quando relacionada ao trauma, inicia-se no local do trauma inicial, progredindo regionalmente sem distribuição dermatomérica específica. $(1,15)$

Aumento na temperatura da pele, alteração de fâneros e fraqueza muscular também podem ocorrer. (14) Com a progressão da doença, os pelos e a temperatura da pele tendem a diminuir, resultando em frialidade do membro afetado. (16) A dor é usualmente desencadeada por estímulos mecânicos, mas fatores psicológicos e estímulos térmicos também podem exacerbar os sintomas. $(15,17)$

\subsection{Critérios diagnósticos da SDRC}

Não existe teste confirmatório específico para SDCR e o diagnóstico permanece incerto. Na tentativa de uma padronização, em 1994, a IASP determinou alguns critérios diagnósticos para SDCR. Porém, esses apresentavam baixa especificidade para a doença. $(18,19)$ Em 2003, foram estabelecidos novos critérios, conhecidos como Critérios de Budapeste, que atualmente permanecem como os critérios mais utilizados para o diagnóstico da SDCR (Quadro 1). (20,21) Os Critérios de Budapeste apresentam alta sensibilidade e melhoraram bastante a especificidade do diagnóstico quando comparados aos critérios da IASP. São eles: (I) presença de dor após um evento desencadeante; (II) alodínia ou hiperalgesia desproporcional a este evento; (III) evidências de alterações cutâneas, disfunção sudomotora ou edema; (IV) ausência de outras evidências que expliquem os sintomas. (20) 
Quadro 1 - Critérios de Budapeste

Dor contínua desproporcional ao evento desencadeante associada a:

1) Pelo menos um sintoma, em 3 das 4 categorias seguintes:

- Sensitivo: alodínia ou hiperalgesia

- Vasomotor: assimetria de temperatura, alteração na coloração da pele

- Sudomotor: edema, alterações de sudorese

- Motor/trofismo: perda de mobilidade, perda motora, alterações na pilificação e no crescimento da unha

2) Pelo menos um sinal em pelo menos duas das categorias seguintes, durante o período de avaliação:

- Sensitivo: evidência de hiperalgesia ou alodínea

- Vasomotor: evidência de assimetria de temperatura ou alterações da coloração da pele

- Sudomotor: evidência de edema ou inchaço

- Motor/trofismo: fraqueza ou disfunção motora

Sem outros diagnósticos que justifiquem os sinais ou sintomas do paciente.

Síndrome Dor Complexa Regional tipo I (SDCR tipo I): sem evidência de dano do nervo principal

SíndromeDor Complexa Regional tipo II (SDCR tipo II): com evidência de dano do nervo principal

Fonte: Adaptado de Harden e Bruehl (2005). (20)

\subsection{Tratamento clínico da SDCR}

Devido à fisiopatologia complexa e incerta, o tratamento tido como "padrão-ouro" ainda não foi determinado. Algumas terapias de reabilitação, como Motor imagery (GMI) e terapia de espelho, foram os tratamentos adjuvantes não-medicamentosos que mostraram maiores evidências de benefícios no tratamento da SDCR. $(22,23)$

O tratamento medicamentoso com gabapentina e amitriptilina foi introduzido acreditando-se na existência de componente neuropático secundário na SDCR-I em fase avançada. Estes medicamentos conseguiram diminuir a intensidade da dor nesses pacientes e se mostraram eficazes no tratamento da SDCR. (24) A carbamazepina também foi utilizada em um pequeno ensaio clínico em dose de $600 \mathrm{mg} / \mathrm{dia}$, durante oito dias e se mostrou eficaz. (25)

O uso de outras drogas é empírico e baseado na experiência individual de cada médico de dor. O uso de medicamentos anti-inflamatórios não-esteróidais mostrou-se pouco eficaz no tratamento da SDCR, devido ao efeito curto e temporário. (26) Entre os corticosteróides, a prednisolona mostrou-se eficaz e segura em promover analgesia por intervalo de tempo de até 2 meses na SDCR pós-infarto. $(27,28)$ Apesar desses avanços no tratamento da SDCR, muitas vezes o tratamento medicamentoso convencional não é suficiente para o controle da SDCR. 


\subsection{Tratamento intervencionista da SDCR}

Quando há falha, refratariedade ou intolerância ao tratamento conservador, técnicas intervencionistas minimamente invasivas são utilizadas para controle dos sintomas de pacientes com SDRC. (2)

Estimuladores de medula e estimuladores de gânglio de raiz dorsal, através do estímulo elétrico no corno dorsal da medula e no gânglio de raiz dorsal, respectivamente, apresentaram efeitos positivos em relação à diminuição da sensação e da percepção dolorosa na SDRC e, principalmente, nas síndromes dolorosas associadas ao pós-operatório de cirurgias de coluna, conhecidas como "failed back pain syndrome". (30) Entretanto, além do alto custo e da maior complexidade de execução, são tratamentos que ainda exigem maiores evidências para recomendação.

Os bloqueios de gânglios simpáticos são comumente empregados por médicos intervencionistas em dor, devido à alteração da desregulação autonômica no membro afetado e resposta exagerada às catecolaminas, contribuindo para o quadro doloroso na SDCR. Em uma revisão recente atualizada por O'Connell et al. (31), os autores não conseguiram afirmar ou refutar o uso dos bloqueios simpáticos para o tratamento da SDCR, devido à qualidade geral dos estudos e ao pouco nível de evidência científica nos tratamentos utilizados. Sendo assim, mais estudos controlados e randomizados são necessários para comprovar a eficácia desse tipo de intervenção nas SDCR.

O tratamento convencional da SDCR, segundo revisão da literatura, inclui a realização de bloqueios autônomos associados ao bloqueio do tecido neuropático. (32-36) Em acordo com a literatura, a Clínica para o Tratamento da Dor- Hospital das Clínicas, da Faculdade de Medicina de Ribeirão Preto, Universidade de São Paulo (CTDor- HC- FMRP-USP) vem tratando, ao longo dos últimos 20 anos, pacientes portadores de SDCR com realização de bloqueios da cadeia simpática responsável pela manuntenção da doença. Esse tratamento ocorre uma vez por semana, durante quatro semanas consecutivas. Quatro semanas é o número médio de semanas de tratamento, podendo variar de três a cinco semanas dependendo da resposta clínica do paciente. Esse tratamento implica em quatro internações, em média, por paciente para realizações dos bloqueios no centro cirúrgico. Esta sequência de bloqueios, em geral, é repetida uma vez por semestre até o controle da dor e da doença, em acordo com outros autores. (32-36) Dessa maneira, são necessárias de seis a 10 internações para a realização dos bloqueios por paciente, sendo oito internações o número médio em um período de 12 meses de tratamento. 
Um alternativa para aumentar a durabilidade do bloqueio seria a técnica de tratamento de neuroablaçao por radiofrequência (RF). Essa técnica promove a neuroablação e neuromodulação das estruturas alvo por um tempo mais prolongado do que a técnica convencial. (37)

\subsubsection{Radiofrequência}

O emprego da RF no tratamento da dor de origem espinhal iniciou-se com Shealy, em 1975, que realizava a lesão do ramo medial para dor de origem facetária na região lombar ou cervical. (38) $\mathrm{Na}$ ocasião, ele lançou mão de um eletrodo com diâmetro de 14 gauge, introduzido por meio de uma agulha 12 gauge, um instrumento de calibre muito grosseiro em comparação aos mais modernos da atualidade. Nos anos 1980 foram introduzidos eletrodos de pequeno diâmetro, sendo que o sistema desenvolvido na ocasião consistia em uma cânula de calibre 22 gauge acoplada a um fino eletrodo inserido nessa cânula, permitindo lesões mais circunscritas e pontuais, como a possível lesão no compartimento anterior (gânglio da raiz dorsal, ramo comunicante, cadeia simpática) com maior precisão e menor risco de lesões por desaferentação ou problemas de danos a fibras motoras secundários a grandes lesões. $(39,40)$ Indica-se a lesão por RF após comprovação do efeito analgésico transitório de bloqueios testes realizados com anestésico local. $(39,41-43)$

\subsubsection{Radiofrequência: mecanismos de ação}

A RF é uma técnica minimamente invasiva alvo-seletiva utilizada para o tratamento da doença dor crônica. Trata-se da utilização de corrente elétrica alternada com frequência oscilatória de $500.000 \mathrm{~Hz}$, a qual flui através de um eletrodo introduzido de forma percutânea. (41)

As técnicas de neuroablação, utilizando sinais de RF, são cada vez mais utilizadas, com resultados muito satisfatórios no controle da dor. Embora exista na prática clínica há mais de 30 anos, evidências sobre segurança e eficácia ainda estão sendo discutidas atualmente. $(43,44)$ A neuroablação por RF utilizando altas temperaturas, a denominada RF convencional ou ablativa, promove destruição de células nervosas, levando a processos de desaferentação. A RF convencional por termocoagulação funciona através da exposição de nervos ou tecidos a estimulação elétrica contínua, provocando ablação dessas estruturas pelo aumento da temperatura no tecido ao redor da ponta da agulha de RF. (41) Este problema é minimizado 
quando a técnica é aplicada em fibras nociceptivas C e quando são evitadas fibras mielinizadas.

\subsubsection{Radiofrequência ablativa: lesão por corrente iônica}

$\mathrm{Na}$ RF ablativa a densidade da corrente elétrica e voltagem se concentram ao redor da ponta ativa da agulha, obedecendo um diâmetro ao redor da mesma para causar um raio de lesão pré-determinada, dependendo do calibre da agulha selecionada (Figura 1). Forma-se calor pela passagem da corrente de RF através dos tecidos que, uma vez aquecidos a uma temperatura préselecionada, agem como um resistor e aquecerão a ponta ativa da agulha de RF, sendo a seguir o calor dissipado pelo chamado eletrodo ou parte passiva da mesma agulha. O tecido aquecerá e transmitirá secundariamente o calor ao eletrodo, aquecendo-o. O mecanismo de aquecimento é, portanto, iônico, ao invés de dielétrico. $(46,47)$

Figura 1 - Configuração da lesão térmica na ponta da agulha de radiofrequência. A lesão apresenta-se como uma pera com a base proximal na ponta ativa, diâmetro aproximado de lesão térmica $3 \mathrm{~mm}$

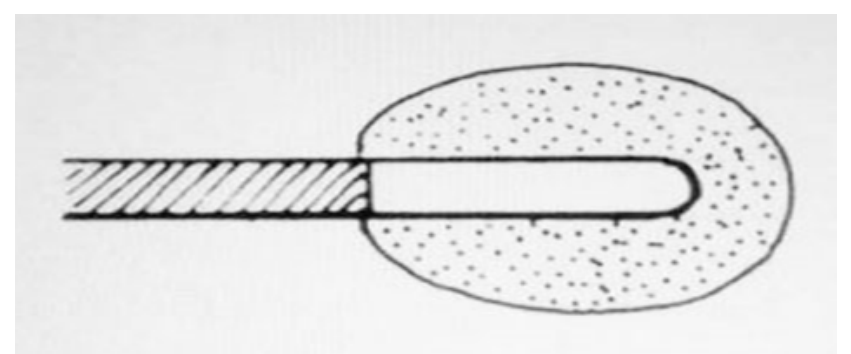

Fonte: Adaptado de Braun e Braun (2009). (48)

Se o eletrodo apresentar um design correto e estiver adequadamente posicionado, sua ponta ativa não absorverá muito calor em estado de equilíbrio. Dessa forma, a temperatura da ponta ativa será aproximadamente a da área de maior calor tissular. Para a realização de uma lesão segura e de tamanho previsível, é de fundamental importância a escolha de um eletrodo de ponta ativa adequada e ter um controle rígido da temperatura de lesão. (49)

A formação de calor será maior onde houver maior densidade de corrente elétrica, ou seja, ao redor da ponta do eletrodo e onde estará o tecido alvo de lesão por RF. A corrente se dispersa de maneira uniforme a partir da ponta ativa da agulha, alcançando maior densidade na porção proximal na qual há uma área maior para saída da corrente. Desse modo, a lesão adquirirá uma conformação em forma de pêra com sua base ao redor da porção proximal da ponta ativa e muito pouca lesão adiante da porção distal. Como a ponta ativa do eletrodo 
promoverá mais lesões transversalmente, o eletrodo é posicionado paralelamente ao tecido alvo, com o objetivo de aperfeiçoar a lesão térmica ao se utilizar a RF contínua. (47) Este conhecimento permite o posicionamento adequado da agulha e a lesão alvo do tecido almejado, evitando lesões por contiguidade ou proximidade.

A relação entre o gerador de RF e a temperatura atingida na ponta do eletrodo não se faz de forma direta. A temperatura final será determinada por variáveis relativas à sua produção e por sua dissipação. Um fator importante na produção de calor é a impedância (resistência à corrente alternada), que varia de acordo com os diferentes tecidos corporais. Essa produção oscila de forma diretamente proporcional à impedância. Outra variável relevante é a dissipação ou eliminação do calor, que depende de dois fatores principais: a condutividade do tecido e a sua vascularização, pois o fluxo sanguíneo dissipa o calor da área aquecida. Como ambos variam muito, a temperatura deve ser medida para se saber o resultado final entre a formação de calor e sua dissipação. (50)

A lesão térmica por RF tem duas fases: durante a primeira, é necessária uma grande produção de energia para elevação inicial da temperatura. Quanto menor a impedância, maior potência de corrente elétrica deverá ser gerada. A voltagem, nesta fase, oscila entre 25 e $60 \mathrm{~V}$. Ao se alcançar a temperatura desejada, inicia-se a segunda fase, cuja carga elétrica do gerador é gradualmente diminuída a um nível de equilíbrio para compensar a dissipação de calor. $(47,51)$

Em camundongos, a RF por termocoagulação no gânglio simpático lombar mostrou-se efetiva no alívio da dor por neuropatia diabética, por provável inibição espinhal da micróglia e consequente menor expressão de fatores inflamatórios. (52)

Desde que começou a ser utilizada, a técnica de ablação por RF já foi extrapolada para diversas áreas da medicina. A mesma parece promover resposta antigênica de células $\mathrm{T}$, aumentando o efeito da imunoterapia em ensaios pré-clínicos em ratos. Da mesma maneira, lesão ablativa incompleta promoveu crescimento tumoral e diminui a eficácia da terapia antiPD-1. Análises imunológicas revelaram que a lesão incompleta por RF provoca inflamação local sustentada com predomínio de células supressores mielóides, as quais inibiriam a atividade das células $\mathrm{T}$ em células neoplásicas. (53)

Os efeitos da ablação por RF também foram estudados na parede ventricular, e mostraram que a ablação deve ser realizada obedecendo a alguns parâmetros, a fim de evitar danos. (54) 


\subsubsection{Radiofrequência pulsada}

Na tentativa de diminuir os efeitos colaterais deletérios da RF por ablação, técnicas mais atrativas de RF utilizando temperaturas mais próximas das fisiológicas foram testadas. A técnica de RF convencional, que consistia em calor aplicado continuamente ao tecido nervoso ao redor da ponta da agulha, foi modificada para ser aplicada na forma de pulsos e o poder neuroablativo tornou-se mais uma opção. $(43,45)$ Assim, a técnica de RF pulsada foi descrita como técnica minimamente destrutiva, (55) na qual não é necessário atingir altas temperaturas, diminuindo o caráter lesivo da técnica e, com isso, poderia ser utilizada em nervos periféricos com componentes misto motor e sensitivo, sem maiores preocupações. Diferentemente da RF convencional ou ablativa, a RF pulsada age promovendo estímulos elétricos curtos, intervalados por uma longa pausa, com objetivo de não provocar calor suficiente que causaria dano tecidual ou nervoso. (56)

Durante a RF pulsada, a agulha é avançada em direção ao nervo através de técnica descrita para cada procedimento, e a sensação de formigamento ou disestesia deve ser testada e reportada sob uma voltagem entre 0,2 a $0,8 \mathrm{~V}$, idealmente. Diversas temperaturas foram testadas e concluiu-se que, se mantida temperatura tecidual ao redor de $42^{\circ} \mathrm{C}$ de média, o efeito neuromodulador resultaria em benefícios com menor potencial de dano tecidual. (57)

O uso da RF pulsada tem sido observado no tratamento de diversas condições dolorosas, como dor radicular, neuralgia occipital, neuralgia do trigêmeo. (58) O desafio está em indicar os parâmetros ideais da RF pulsada na prática clínica, além dos mecanismos de ação que ainda precisam ser mais bem esclarecidos.

A RF pulsada parece atuar provocando lesões relativamente maiores em fibras sensitivas C e A delta em detrimentos de fibras não sensitivas. (59) A RF pulsada também ativa a via descendente inibitória (serotoninérgica e noradrenergica) inibindo fibras excitatórias do tipo C. (60)

O gânglio da raiz dorsal representa a primeira estrutura quando se fala em modulação da dor. Sendo assim, é o alvo de várias novas terapias para controle de dor neuropática, sendo uma delas a radiofrequência, pelo perfil seguro, eficaz e pouco invasivo. A eficácia e segurança da RF pulsada próxima ao gânglio da raiz dorsal já e bem documentada em nível cervical e lombar. A duração do efeito é menor que na RF convencional, porém sem complicações neurológicas descritas. (58)

Outro efeito considerado da técnica de RF pulsada é a ação na micróglia. Micróglia são os macrófagos residentes no sistema nervoso central e que reagem aos diversos estímulos que 
alteram a homeostase e induzem alterações patológicas. $(61,62)$ A ativação da micróglia pode induzir sensibilização central e manter a dor. $(63,64)$ Em 2013, Cho et al. (65) perceberam a diminuição da ativação da micróglia no corno dorsal da medula após aplicação da RF pulsada no gânglio da raiz dorsal. A micróglia pode causar dor crônica tipo neuropática pela liberação de várias substâncias, como citocinas, que estão relacionadas à sinalização da dor. Sendo assim, uma regulação para baixo da micróglia poderia prevenir o desenvolvimento de dor crônica tipo neuropática. Citocinas pró-inflamatórias como fator de necrose tumoral alfa (TNF- $\alpha$ ) - e interleucina 6 (IL-6) estavam diminuídas após a aplicação de RF pulsada. (66) Também foi demonstrada que a RF pulsada em espaço peridural caudal reduziu alodínia e diminuiu a atividade da micróglia e a expressão dos CGRP nos discos lombares herniadas e nos níveis espinhais adjacentes em modelos de camundosogos com hérnia de disco. (67)

A literatura ainda não é consistente quando se fala dos efeitos adversos da técnica de RF pulsada no tratamento da dor crônica. $(55,68)$ A maioria dos estudos são direcionados para os efeitos da técnica no controle da dor, porém sem aprofundar nos efeitos morfológicos e celulares. (45) Existem relatos de desenvolvimento de dor tipo neuropática paradoxalmente após a aplicação de RF para tratamento de dor neuropática. $(69,70)$

Apesar da necessidade de mais estudos para estabelecer parâmetros ideais, a técnica de $\mathrm{RF}$, é extremamente interessante na terapêutica da dor, visto que é relativamente fácil de ser executada por profissionais devidamente capacitados. A mesma apresenta efeito analgésico por diversos mecanismos e parece ser mais custo-efetiva que outras técnicas que utilizam apenas anestésicos locais associadas a corticosteroides. Além disso, a manipulação do gânglio dorsal parece promissor como coadjuvante na terapêutica da dor crônica. (71) 


\section{JUSTIFICATIVA}

Considerando o fato de a SDCR-I ser uma condição neurológica crônica e de fisiopatologia complexa e incerta não existe consenso na literatura sobre o tratamento ideal para alívio da dor de forma mais eficaz e duradoura.

O tratamento medicamentoso com gabapentina e amitriptilina tem se mostrado eficaz no tratamento da SDCR. Porém, apresenta efeito curto e temporário no controle da dor. $\mathrm{O}$ tratamento convencional, através da realização de bloqueios da cadeia simpática responsável pela manuntenção da doença, implica em uma média de oito internações em um período de 12 meses de tratamento da dor.

Em contrapartida, o tratamento utilizando RF tem se mostrado promissor e satisfatótio no controle da dor, apresentado resultados mais duradouros, bem como aumentando o tempo de analgesia e reduzindo, consequentemente, o número de internações, a exposição ao ato anestésico e o consumo de analgésicos para o controle da dor diária em pacientes submetidos a técnica de RF. Essas técnica portanto, pode apresentar melhor custo benefício em relação ao tratamento convencional.

Dessa forma, a comparação entre o tratamento convencionalmente realizado no CTDorHC- FMRP-USP e a utilização de RF para o tratamento da dor se faz necessário a fim de se estabelecer as vantagens de uma técnica sobre a outra em pacientes portadores de SDCR-I. Além do efeito analgésico da técnica propriamente dita, é essencial a determinação dos custos para a realização da técnica proposta utilizando RF e a comparação com os custos da técnica convencional atualmente empregada para determinar a viabilidade de sua utilização no CTDorHC- FMRP-USP. 


\section{OBJETIVOS}

\subsection{Objetivo Geral}

Avaliar o efeito analgésico e os custos financeiros da modulação do gânglio dorsal associada à ablação convencional do gânglio simpático, utilizando a técnica de radiofrequência, em pacientes portadores de SDCR-I, em comparação ao tratamento convencional atualmente empregado.

\subsection{Objetivos específicos}

1) Comparar a efetividade analgésica das duas técnicas tendo como parâmetros o consumo de analgésicos e o tempo de analgesia adequada e inadequada;

2) Comparar a qualidade de vida dos pacientes portadores de SDCR-I, através do padrão de sono noturno e de sua capacidade para realização de atividades rotineiras durante tempo de analgesia adequada e inadequada;

3) Avaliar comparativamente os custos financeiros entre a técnica convencional e o uso da RF para o tratamento da dor em pacientes portadores de SDCR-I. 


\section{MATERIAL E MÉTODOS}

\subsection{Local de realização dos procedimentos e delineamento experimental}

O estudo foi realizado na CTD- HC- FMRP-USP. Os bloqueios testes e as ablações por RF foram realizadas no Centro de Endoscopia, onde a CTD- HC- FMRP-USP possui horário fixo com intensificador de imagem disponível.

O trabalho foi aprovado do Comitê de Ética em Pesquisa do Hospital das ClínicasFaculdade de Medicina de Ribeirão Preto - Universidade de São Paulo (Processo HC1430/2010). O estudo foi prospectivo, aleatório, duplamente-encoberto, sendo que cada paciente atuou como seu próprio controle (avaliação Crossover). A distribuição entre os dois grupos foi realizada de forma aleatória através de uma sequência randomizada gerada por computador. O tempo total de estudo para cada paciente foi de até 24 meses, desde a entrada do mesmo no protocolo de pesquisa proposto, uma vez que cada paciente participou dos dois grupos do estudo descritos no item 3.5.

\subsection{População de estudo}

Pacientes portadores de SDCR-I atendidos pela CTD-HC-FMRP-USP, com história clínica compatível com SDCR-I, baseado nos critérios de Budapeste. (20) Primeiramente, os pacientes foram contatados no ambulatório da CTD onde foram examinados. Os pacientes foram então informados sobre os procedimentos e o protocolo do estudo, e selecionados para participação após os esclarecimentos e aceitação formal (Anexo A). Os pacientes selecionados compareceram nas datas agendadas para os procedimentos, de acordo com cada grupo de estudo, em jejum de oito horas para alimentos sólidos e líquidos, acompanhado de pessoa maior de idade.

\subsubsection{Critérios de inclusão}

Os critérios de inclusão para os pacientes do presente estudo foram: pacientes adultos, com idades entre 21 e 80 anos, de ambos os gêneros, portadores de SDCR-I, com história de dor por tempo superior a seis meses de duração e em uso diário de fármacos diversos para o 
controle da dor (como analgésicos, anti-inflamatórios não-esteroidais, relaxantes musculares, anticonvulsivantes, antidepressivos, opióides e dipirona), associado à fisioterapia.

Para o diagnóstico da SDCR-I os sinais e os sintomas foram divididos em grupos distintos. Os critérios utilizados foram descritos por Harden e Bruehl (2005), conhecidos como Critérios de Budapeste. (20) O paciente foi diagnosticado com SDCR-I quando apresentou pelo menos dois dos seguintes sintomas:
a. sensoriais (hiperestesia),
b. vasomotor (alteração da temperatura, coloração ou ambos),
c. sudomotor/balanço líquido (edema, sudorese ou ambos) e,
d. motor (diminuição da motricidade, fraqueza, tremores, amputação funcional do membro) ou todos,
e. ou o paciente deve apresentar ao menos dois dos seguintes sinais: vasomotor, sudomotor/balanço líquido e motor.

\subsubsection{Critérios de exclusão}

Qualquer situação que contraindicasse a realização da ablação por RF ou a realização dos bloqueios testes com anestésico local sem resposta positiva: impossibilidade de realização de bloqueios teste como a infecção na pele, febre, história prévia de crises convulsivas, distúrbio de coagulação, glaucoma, história de infarto cardíaco recente (nos últimos seis meses) ou recusa do paciente. Outros critérios de exclusão foram: pacientes portadores de estenose de canal, e/ou dor classificada como SDCR-II, com componentes de dor definidos como dor neuropática inicial desencadeante.

Pacientes que se recusaram a participar da pesquisa foram tratados pela técnica disponível na CTD-HC- FMRP-USP, ou seja, foram submetidos durante o mesmo período de 12 meses a quatro sequências semanais periódicas de bloqueios realizados como descritos em bloqueios testes, a cada seis meses.

\subsection{Protocolo de Tratamento}

O tratamento inicial ao qual os pacientes foram submetidos foi realizado seguindo parte do protocolo utilizado, baseado em evidência científica, pelos especialistas intervencionistas em dor, como descrito abaixo $(2,22,72)$ : 
1) Tratamento farmacológico associado à fisioterapia para movimentação ativa e passiva do membro afetado;

2) Realização de bloqueios testes (bloqueio peridural sacral + bloqueio gânglio autônomo simpático em L3);

3) Sequência de 3-5 bloqueios do sistema autônomo simpático associado, em intervalos semanais, ou ablação dos gânglios simpáticos autônomos e modulação dos gânglios dorsais por RF.

\subsubsection{Delineamento experimental}

Foram avaliados 36 pacientes portadores de SDCR-I em membro inferior, de forma prospectiva sendo 18 pacientes destinados a cada grupo $(\mathrm{n}=18)$ (Figura 1). Os pacientes foram distribuídos aleatoriamente através de uma sequência randomizada gerada por computador:

1) Grupo 1 - bloqueio peridural sacral + bloqueio gânglio autônomo simpático em L3 (designados como bloqueios testes). Caso a resposta aos bloqueios testes demonstrasse pelo menos 50\% de melhora do valor inicial de Escala Numérica de Dor (END) (0-10 $\mathrm{cm}$ ), prosseguia-se após 14 dias de intervalo para a sequência idêntica de peridural sacral + bloqueio simpático lombar L3, realizados de forma semanal, por quatro semanas consecutivas como descritos no item 4.6.2.

2) Grupo 2- bloqueio peridural sacral + bloqueio gânglio autônomo simpático em L3 (designados como bloqueios testes). Caso a resposta aos bloqueios testes demonstrasse pelo menos 50\% de melhora do valor inicial de END (0-10 cm), prosseguia-se após 14 dias de intervalo para ablação por RF dos gânglios simpáticos autônomos de L3, L4 e L5, associado à modulação por RF dos gânglios dorsais dos mesmos níveis (L3-L4-L5).

Quando a analgesia foi considerada inadequada no bloqueio teste (END $\geq 4 \mathrm{~cm}$ ), o paciente do Grupo 1 reiniciou o estudo como Grupo 2, e vice-versa (Figura 2). 
Figura 2 - Fluxograma inicial da divisão dos grupos experimentais e do estudo no tempo. Escala Numérica de Dor (END): 0-10 cm

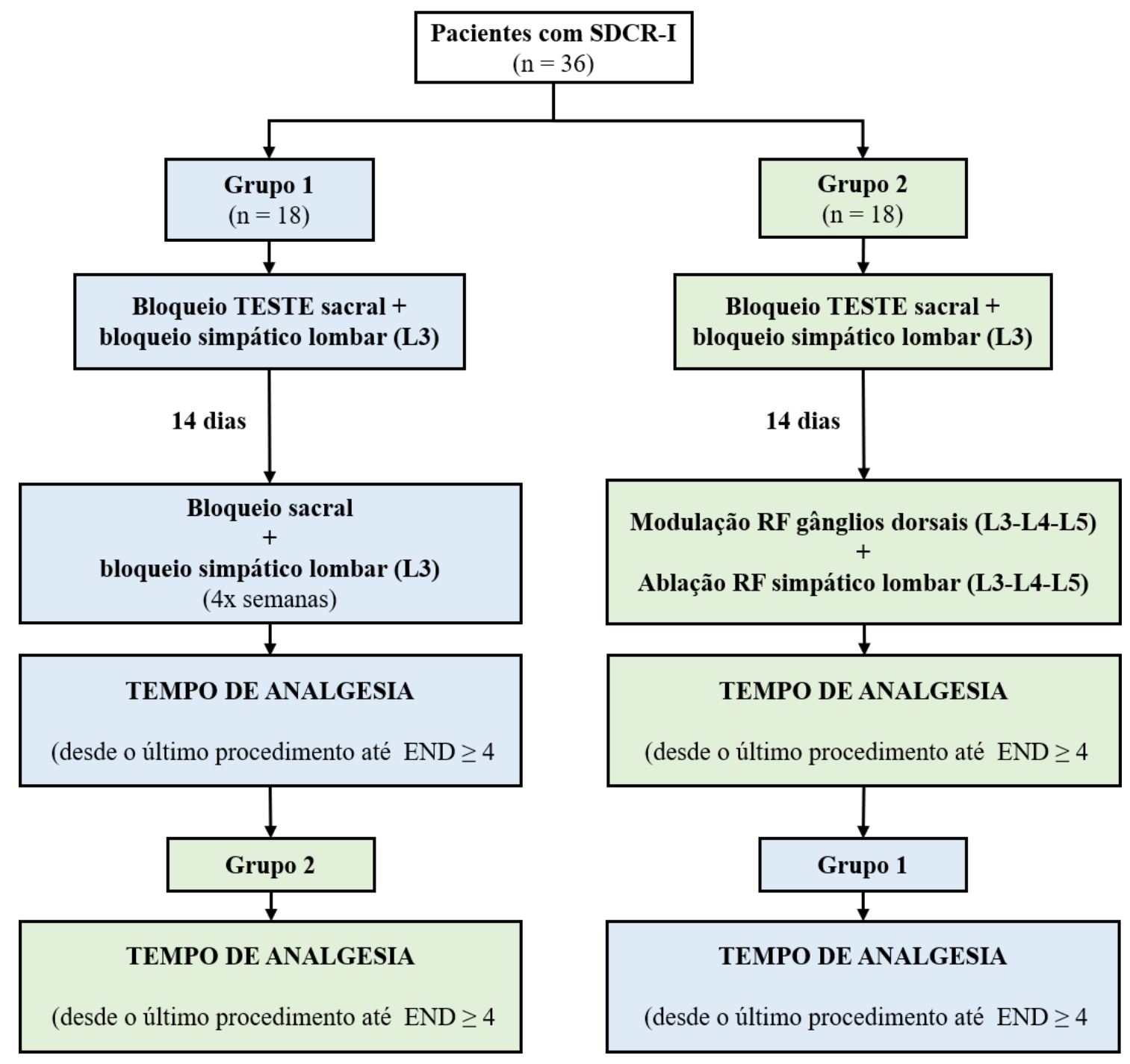

Fonte: Elaborado pelo Autor

\subsection{Fármacos utilizados}

1) Omnipaque ${ }^{\circledR}$ (GE Health Care do Brazil) $300 \mathrm{mg} / \mathrm{mL}$, cada frasco contém $100 \mathrm{~mL}$ de solução de uso injetável (embalagem hospitalar), cada $\mathrm{ml}$ contém $647 \mathrm{mg}$ de ioexol;

2) Lidocaína 1\%, frasco com $20 \mathrm{ml}$, sem vasoconstrictor (Xylestesin ${ }^{\circledR}$, Cristália);

3) Solução fisiológica $0,9 \%$, frasco com $10 \mathrm{ml}$ para uso por via venosa;

4) Duo-Decadron ${ }^{\circledR}$ (Aché), suspensão injetável $(8 \mathrm{mg} / \mathrm{ml}$ acetato de dexametasona +2 $\mathrm{mg} / \mathrm{ml}$ fosfato dissódico de dexametasona); 
5) Alfentanil ${ }^{\circledR}$ (Cloridrato de alfentanil, Cristália), ampola para uso por via venosa contendo $500 \mathrm{mcg} / \mathrm{ml}$, total $5 \mathrm{ml}$;

6) Dormire ${ }^{\circledR}$ (Maleato de Midazolam Cristália) ampola para uso por via venosa contendo $1 \mathrm{mg} / \mathrm{ml}$, volume $5 \mathrm{ml}$.

\subsection{Técnicas de bloqueios}

Os bloqueios foram realizados sob sedação consciente com midazolam ( 2 a $4 \mathrm{mg}$ ) por via venosa, associado ao alfentanil (500 a $1000 \mathrm{mcg}$ ) por via venosa, sedados por um anestesiologista não participante do estudo em sala cirúrgica. Todos os bloqueios foram feitos pelos mesmos especialistas (Intervencionista em Dor), com uso de intensificador de imagem.

O paciente foi posicionado em decúbito ventral, com travesseiro acomodado sob a crista ilíaca para retificação da coluna lombo-sacra. Após assepsia com clorexedina alcoólica, foi realizada a colocação de campos cirúrgicos e os bloqueios foram realizados sob técnica asséptica.

\subsection{Bloqueio peridural por via sacral}

Com o intensificador de imagem inicialmente em perfil, a agulha com calibre 22, 10 $\mathrm{cm}$, foi avançada para dentro do espaço peridural sacral e administrado $0,5 \mathrm{ml}$ de contraste nãoiodado Omnipaque ${ }^{\circledR}$ para verificação do correto posicionamento da mesma (Figura 3). Posteriormente foi administrado $10 \mathrm{mg}$ dexametasona + clonidina $15 \mathrm{mcg}$ + lidocaína $40 \mathrm{mg}$ + lidocaína $40 \mathrm{mg}$, para volume final $10 \mathrm{ml}$. 
Figura 3 - Agulha posicionada no espaço peridural sacral, visão de perfil, após administração de $0,5 \mathrm{ml}$ de contraste não-iodado Omnipaque ${ }^{\circledR}$

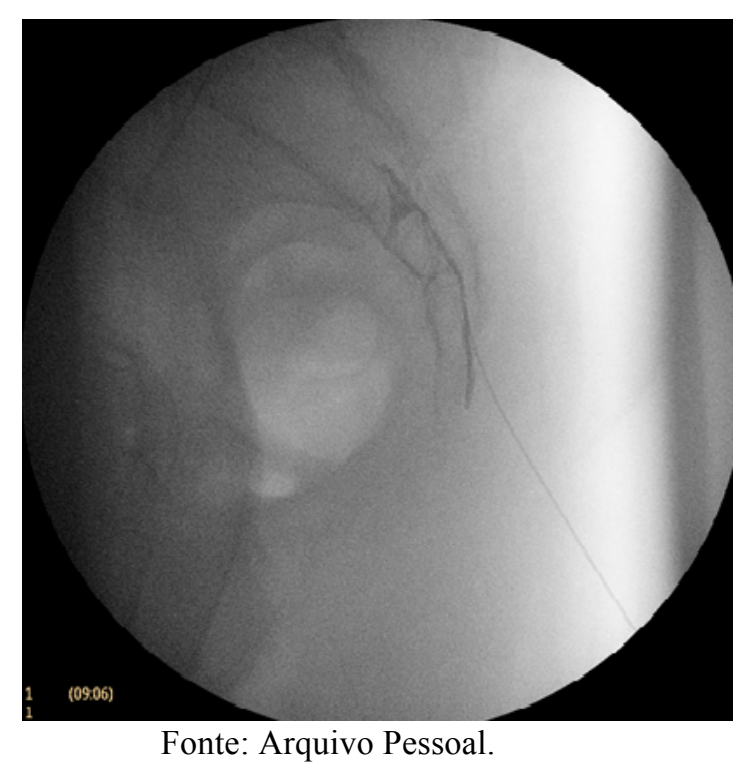

\subsubsection{Bloqueio autônomo simpático lombar}

Os bloqueios simpáticos lombares testes foram realizados em corpo vertebral lombar de L3, inicialmente em oblíquo até visão do pedículo contralateral entre metade e terço medial do corpo vertebral, após retificação do platô vertebral do corpo vertebral de L3, e punção em sua margem superior, em visão de túnel (Figura 4). Em perfil, a agulha foi avançada até que visualmente alcançasse a margem anterior do corpo vertebral de L3. Todos os posicionamentos foram confirmados com administração $0,5 \mathrm{ml}$ de contraste não-iodado (Omnipaque ${ }^{\circledR}$ ) em cada punção para verificação do posicionamento final adequado. Em seguida, foi administrado lidocaína $80 \mathrm{mg}$ + dexametasona $5 \mathrm{mg}$ + clonidina $15 \mathrm{mcg}$, com volume final $10 \mathrm{ml}$ (diluição de clonidina e dexametasona foram realizadas com SF 0,9\%). 
Figura 4 - Bloqueio simpático lombar L3, visão oblíqua

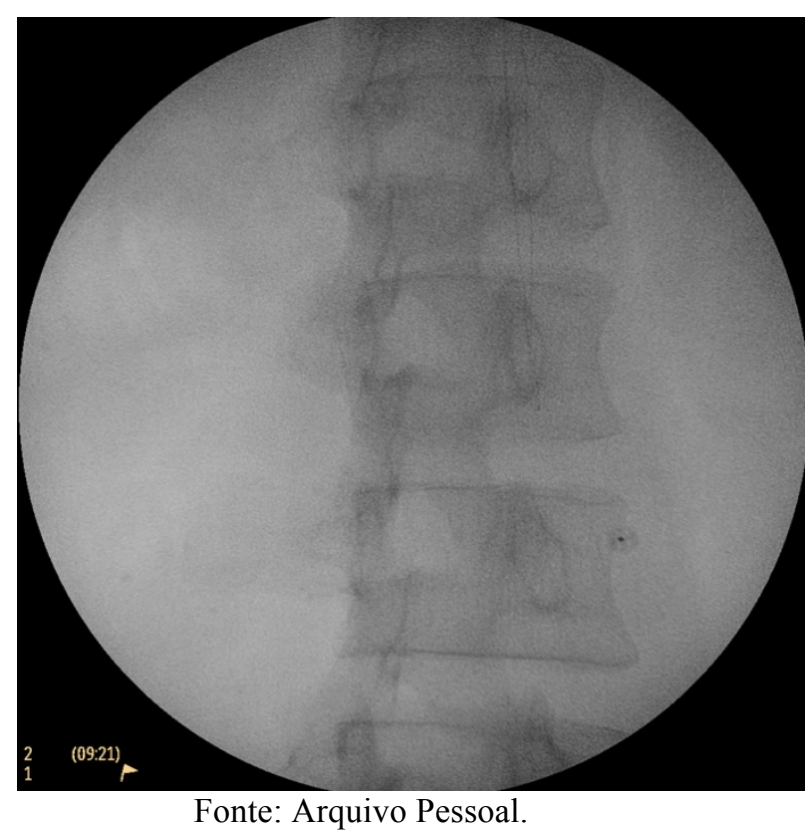

\subsubsection{Bloqueio do gânglio dorsal transforaminal lombar}

Os bloqueios do gânglio dorsal L3-L4, L4-L5 e L5-S1 do lado acometido foram realizados inicialmente em oblíquo, com colocação visual do pedículo no primeiro terço do corpo vertebral visualmente, associado à retificação de cada platô vertebral. A agulha foi posicionada em visão de túnel logo abaixo do pedículo, direcionado para o forame de cada espaço (Figura 5), e, então, progredida em visão de perfil até que visualmente ficasse posicionada no terço posterior superior do mesmo (Figura 6). Todos os posicionamentos foram confirmados com administração $0,5 \mathrm{ml}$ de contraste não-iodado (Omnipaque ${ }^{\circledR}$ ) em cada punção para verificação do posicionamento final adequado. Posteriormente, foi administrado em cada punção 3,3 ml de solução final contendo: $10 \mathrm{mg}$ dexametasona + clonidina $15 \mathrm{mcg}$ + lidocaína $80 \mathrm{mg}$ para volume final $10 \mathrm{ml}$. 
Figura 5 - Bloqueio gânglio dorsal lombar L4, L5, visão oblíqua

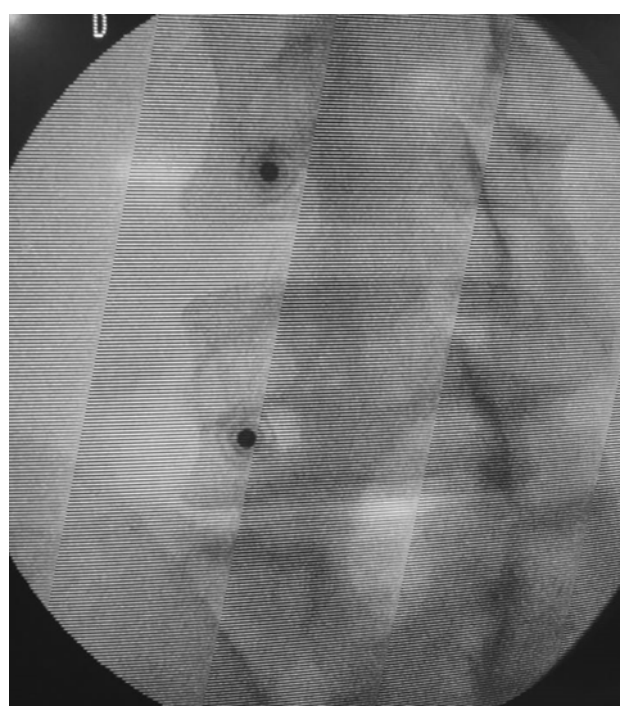

Fonte: Arquivo Pessoal.

Figura 6 - Bloqueio gânglio dorsal lombar L4, L5, visão de perfil

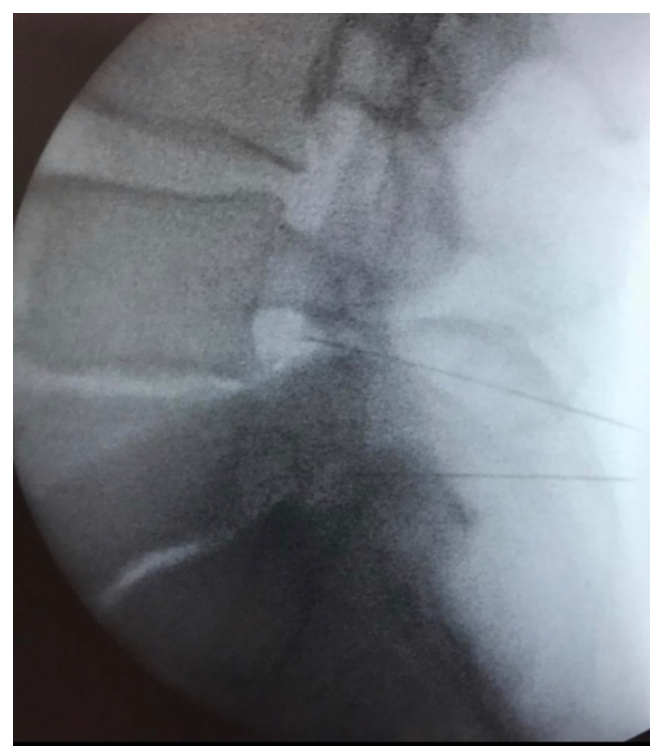

Fonte: Arquivo Pessoal.

\subsubsection{Ablação convencional do gânglio simpático lombar de L3, L4 e L5 do lado acometido}

Após posicionamento das agulhas em margens superiores dos corpos vertebrais de L3, L4 e L5, e posicionamento em perfil em margens ventrais, foi checada a impedância inferior a $500 \mathrm{Ohms}$, e realizados em cada nível os testes sensorial $(50 \mathrm{~Hz} ; 0,4$ a $0,8 \mathrm{mV}$; duração de pulso 1 milisegundo) e motor ( $2 \mathrm{~Hz}, 0,4$ a 1,6 V), sendo ambos negativos, para comprovação do correto posicionamento da agulha de RF. Foi, então, administrado 3,3 ml de solução contendo 
$10 \mathrm{mg}$ dexametasona + clonidina $15 \mathrm{mcg}$ + lidocaína $80 \mathrm{mg}$, para volume final $10 \mathrm{ml}$, seguida de ablação por RF com temperatura $80{ }^{\circ} \mathrm{C}$, por 70 segundos em cada nível (Figura 7).

Figura 7 - Posicionamento percutâneo das agulhas de radiofrequência na região lombar anterior aos corpos vertebrais de L3, L4 e L5, visando os gânglios simpáticos lombares correspondentes

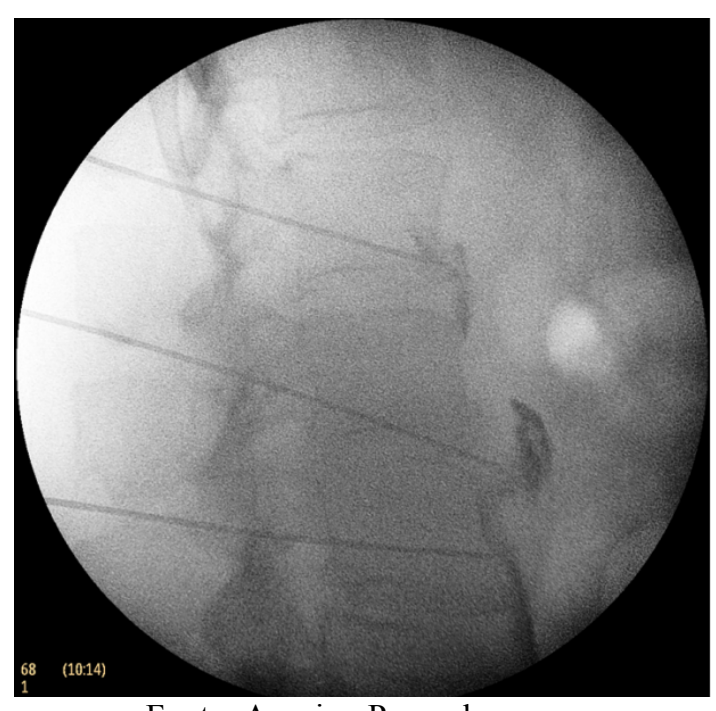

Fonte: Arquivo Pessoal.

\subsubsection{Modulação do gânglio dorsal transforaminal}

Após posicionamento das agulhas abaixo do pedículo dos corpos vertebrais de L3-L4, L4-L5 e L5-S1, em oblíquo, e posicionamento em perfil transforaminal, em região póstero superior de cada forame, foi checada a impedância inferior a $500 \mathrm{Ohms}$ e realizados em cada nível os testes sensorial ( $50 \mathrm{~Hz}$; 0,4 a $0,8 \mathrm{mV}$; duração de pulso 1 milisegundo) e motor (2 Hz, 0,8 a 1,6 V), sendo o motor negativo para a intensidade alcançada no teste sensitivo para comprovação do correto posicionamento da agulha de RF. Posteriormente foi administrado 3,3 $\mathrm{ml}$ de solução contendo $10 \mathrm{mg}$ dexametasona + clonidina $15 \mathrm{mcg}$ + lidocaína $80 \mathrm{mg}$ para volume final $10 \mathrm{ml}$. Seguida de modulação por RF, $45 \mathrm{~V}$, com temperatura $42{ }^{\circ} \mathrm{C}$, por 120 segundos em cada nível (Figura 5).

\subsection{Análise demográfica da população do estudo}

Foram avaliadas na população do estudo, através de questionário realizado durante consulta, as seguintes características demográficas: patologias de base, gênero, etnia, idade, peso, altura, tempo de dor, medicamentos em uso, religião ou crença, qualidade do sono, capacidade de realizar atividades rotineiras. 


\subsection{Avaliação da dor}

A dor foi avaliada regularmente, nos retornos semanais e mensais, através dos seguintes parâmetros:

1) Intensidade da dor. Inicialmente a intensidade de dor foi avaliada utilizando-se a END de $10 \mathrm{~cm}$, sendo o extremo " 0 (zero) cm" correspondente a "ausência de dor", variando até "10 cm", correspondente a "pior dor imaginável". Foram rotineiramente prescritas as medicações que cada paciente já utilizava regularmente para o controle da dor, sendo o paciente livre para a ingestão dos fármacos analgésicos de resgate caso a dor diária fosse considerada inadequada ou seja, persistisse na escala numérica de dor superior a três cm, ou seja, igual ou maior que quatro $(\geq 4 \mathrm{~cm})$. Pacientes que apresentavam valores iguais ou superiores a quatro $\mathrm{cm}$ na escala END $(\geq 4 \mathrm{~cm})$ tiveram a analgesia considerada inadequada e o tempo desde a realização do procedimento até o paciente considerar a analgesia como inadequada foi medido em meses;

2) Tipo de dor (queimação, formigamento, agulhada, choque ou outro);

3) Tempo de analgesia após bloqueio (desde a realização do procedimento até a primeira ingestão do analgésico) e consumo diário de comprimidos analgésicos após bloqueio;

4) Tempo de analgesia após realização da ablação por RF (desde a realização do procedimento até a primeira ingestão do analgésico) e consumo diário de comprimidos analgésicos após RF.

\subsection{Avaliação da qualidade de sono e atividades diárias}

A qualidade do sono e a capacidade para realizar atividades diárias foram avaliadas regularmente nos retornos semanais e mensais através de:

a. Escala Numérica de Sono 0-10 cm (ENSono 0-10cm) onde 0 (zero) corresponde a "sono reconfortante, agradável e adequado" até 10, o qual corresponde a "pior sono possível, insônia grave”. 
b. Escala Numérica de Capacidade 0-10 cm (ENCap 0-10 cm), onde 0 (zero) corresponde a "totalmente capaz" até 10, o qual corresponde a "totalmente incapaz".

\subsection{Avaliação do custo financeiro durante as fases de bloqueio teste e de radiofrequência}

O custo para a realização dos procedimentos foi avaliado e quantificado de forma detalhada considerando os dados do Sistema Único de Saúde (SUS). Esses valores incluem os custos com material e pessoal. Foi avaliado além do custo financeiro de cada internação o custo anual por paciente para cada um dos grupos do estudo.

\subsection{Avaliação dos efeitos adversos}

Quaisquer efeitos adversos foram observados, descritos de forma espontânea pelo paciente e tratados pela equipe médica.

\subsection{Análise estatística e determinação do número amostral}

A determinação do número mínimo de 22 pacientes por grupo do estudo baseou-se na avaliação do teste do poder estatístico, considerando $\beta 80 \%$ e $\alpha 0,05$ para o tempo de analgesia descrito como END $<$ a $4 \mathrm{~cm}$. Entretanto, foram selecionados 36 pacientes, para garantir o número mínimo, considerando possíveis exclusões. A distribuição de normalidade das amostras foi avaliada foi teste de Shapiro-Wilk. A análise demográfica foi realizada de forma descritiva. Foi utilizado o teste de Wilcoxon para avaliação do tempo de analgesia entre os grupos 1 e 2, assim como para os valores numéricos de END. A incidência de efeitos adversos, qualidade do sono, capacidade para realizar atividades de rotina e utilização de fármacos adjuvantes também foram comparadas pelo teste de Wilcoxon, sendo $p<0,05$ considerado significativo. 


\section{RESULTADOS}

\subsection{Descrição demográfica}

Cada paciente atuou como seu próprio controle nesse estudo prospectivo. Do total de 36 pacientes, somente 24 participaram da avaliação final. Dois pacientes foram excluídos devido a dados incompletos. Cinco pacientes apresentaram dificuldades para comparecerem acompanhados ou, mesmo, no transporte até o Hospital para a realização dos procedimentos nas datas propostas. Outros cinco pacientes não responderam aos bloqueios de forma satisfatória e foram selecionados para implante de estimulador de medula espinal (SCS). O fluxograma final, contendo a dinâmica de cada grupo após a exclusão desses pacientes, está descrito na Figura 8.

Figura 8 - Fluxograma final do estudo

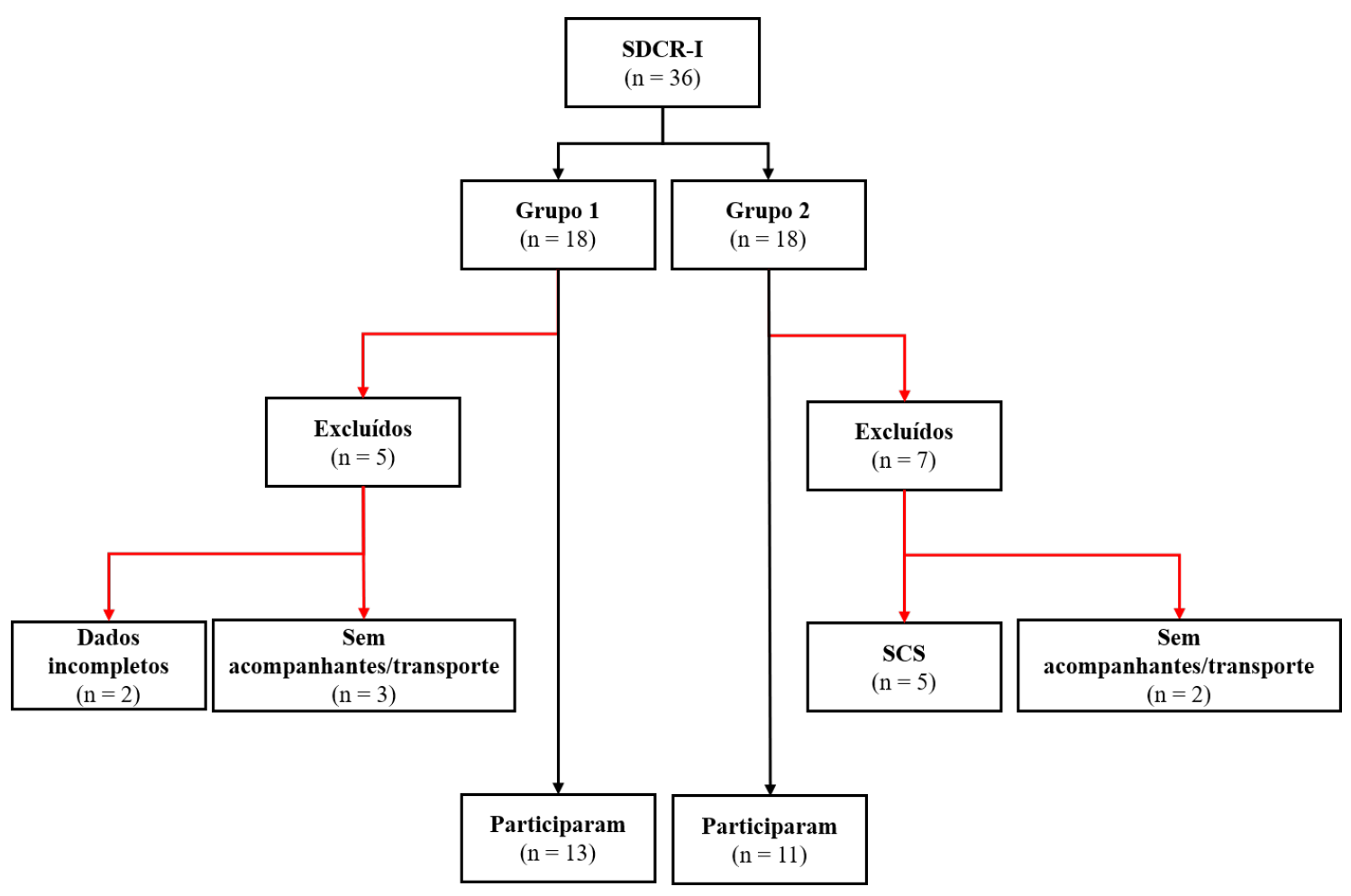

Fonte: Elaborado pelo Autor

As características demográficas da população do estudo estão descritas na Tabela 1. A idade média observada foi de 46,04 anos $( \pm 9,57)$, com média de peso de $71,96 \mathrm{Kg}( \pm 15,79)$ e altura de $165,79 \mathrm{~cm}( \pm 7,79)$. A maioria dos pacientes pertence ao gênero masculino $(52 \%)$, de etnia branca $(66,67 \%)$ e tendo como religião o catolicismo $(66,67 \%)$. Em relação a dor, o tempo 
médio de dor observado nos pacientes foi de 10,42 meses $( \pm 6,61)$. Todos os pacientes relataram o uso de antidepressivos, sendo a amitriptilina o mais utilizado $(75 \%, 18 / 24)$. A gabapentina também é utilizada por $100 \%$ da população do estudo (24/24), seguido da metadona (50\%, $12 / 24)$ e da carbamazepina $(33,33 \%, 8 / 24)$.

Tabela 1 - Dados demográficos dos pacientes diagnosticados com SDCR-I incluídos no estudo, segundo idade (anos), peso $(\mathrm{Kg})$, altura $(\mathrm{cm})$, tempo de dor (meses), religião, gênero, etnia e uso de medicamentos

\begin{tabular}{|c|c|c|}
\hline \multicolumn{3}{|c|}{ CARACTERÍSTICAS DEMOGRÁFICAS } \\
\hline \multicolumn{3}{|c|}{ Idade (anos) } \\
\hline $\begin{array}{l}\text { Média (DP) } \\
\text { mín - máx }\end{array}$ & \multicolumn{2}{|c|}{$\begin{array}{c}46,04( \pm 9,57) \\
23-65\end{array}$} \\
\hline \multicolumn{3}{|l|}{ Peso corporal $(\mathrm{Kg})$} \\
\hline $\begin{array}{l}\text { Média (DP) } \\
\text { mín - máx }\end{array}$ & \multicolumn{2}{|c|}{$\begin{array}{l}71,96( \pm 15,79) \\
54-121 \\
\end{array}$} \\
\hline \multicolumn{3}{|l|}{ Altura (cm) } \\
\hline $\begin{array}{c}\text { Média (DP) } \\
\text { mín - máx }\end{array}$ & \multicolumn{2}{|c|}{$\begin{array}{l}165,79( \pm 7,79) \\
153-178\end{array}$} \\
\hline \multicolumn{3}{|l|}{ Tempo de dor (meses) } \\
\hline $\begin{array}{l}\text { Média (DP) } \\
\text { mín - máx }\end{array}$ & \multicolumn{2}{|c|}{$\begin{array}{c}10,42( \pm 6,61) \\
5-36 \\
\end{array}$} \\
\hline \multirow[t]{3}{*}{ Religião } & $f$ & $\%$ \\
\hline & 16 & 66,67 \\
\hline & 8 & 33,33 \\
\hline TOTAL & 24 & $\mathbf{1 0 0 , 0 0}$ \\
\hline \multirow[t]{3}{*}{ Gênero } & $f$ & $\%$ \\
\hline & 13 & 52,00 \\
\hline & 11 & 48,00 \\
\hline TOTAL & 24 & 100,00 \\
\hline \multirow[t]{4}{*}{ Etnia } & $f$ & $\%$ \\
\hline & 16 & 66,67 \\
\hline & 8 & 33,33 \\
\hline & 24 & $\mathbf{1 0 0 , 0 0}$ \\
\hline Medicamentos em uso rotineiro & $f$ & $\%$ \\
\hline Antidepressivo & 24 & 100,00 \\
\hline Amitriptilina & 18 & 75,00 \\
\hline Sertralina & 5 & 20,83 \\
\hline Duloxetina & 8 & 33,33 \\
\hline Gabapentina & 24 & 100,00 \\
\hline$\overline{\text { Metadona }}$ & 12 & 50,00 \\
\hline Carbamazepina & 8 & 33,33 \\
\hline
\end{tabular}




\subsection{Avaliação da analgesia}

Os 24 pacientes avaliados referiram dor do tipo queimação no membro inferior acometido. Foi observado edema, alodinia e hiperalgesia associados à dor. No Grupo 1, no qual os pacientes foram submetidos à sequência de quatro bloqueios semanais, a média do tempo de analgesia $(E N D<4 \mathrm{~cm})$ foi de cinco meses e meio, significativamente menor do que a média de tempo de analgesia após a realização de RF nos mesmos pacientes $(p<0,001)(15,5$ meses - Tabela 2, Figura 9).

Tabela 2 - Avaliação da dor em pacientes portadores de SDCR-I, submetidos à sequência de quatro bloqueios semanais (Grupo 1) ou a ablação por radiofrequência (Grupo 2)

\begin{tabular}{cccc}
\hline & GRUPO 1 & GRUPO 2 & p valor \\
& 4 bloqueios & RF & p \\
\hline Tempo de analgesia* (meses) & & & \\
Média (DP) & $5,5( \pm 1,47)$ & $15,5( \pm 2,34)$ & $<\mathbf{0 , 0 0 1}$ ' \\
mín - máx & $3-8$ & $12-20$ & \\
\hline $\mathrm{DP}=$ desvio padrão. & & & \\
w $=$ Teste de Wilcoxon. & &
\end{tabular}

Figura 9 - Tempo de analgesia adequado $($ END $<4)$ em meses após sequência de 4 bloqueios e após RF avaliados em 24 pacientes, sendo que cada paciente atuou como seu próprio controle

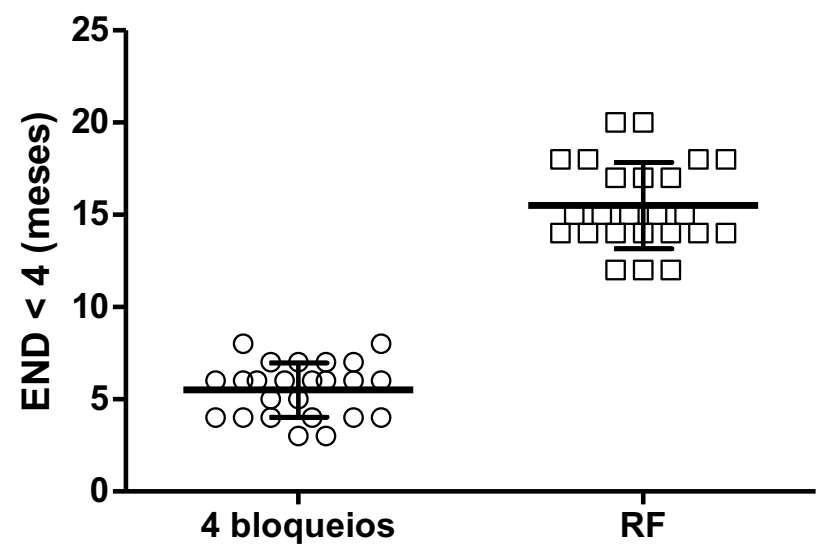

O consumo de analgésicos de resgate (Tramadol $50 \mathrm{mg}$ ) durante o período no qual a analgesia foi considerada adequada $(E N D<4)$ e inadequada $(E N D \geq 4)$ foi semelhante entre os grupos (Tabela 3). 
Tabela 3 - Avaliação do consumo de analgésicos de resgate (Tramadol) durante os períodos de analgesia adequada e inadequada em pacientes portadores de SDCR-I

\begin{tabular}{|c|c|c|c|}
\hline & $\begin{array}{l}\text { Período de analgesia } \\
\text { inadequada } \\
(E N D \geq 4)\end{array}$ & $\begin{array}{c}\text { Período de analgesia } \\
\text { adequada } \\
(\text { END }<4)\end{array}$ & $p$ valor \\
\hline \multicolumn{3}{|c|}{ Avaliação do consumo de analgésicos de resgate* } & \multirow{3}{*}{$>0,05^{W}$} \\
\hline Mediana $(25 P-75 P)$ & $4(4-5)$ & $1(1-2)$ & \\
\hline mín - máx & $2-6$ & $0-2$ & \\
\hline
\end{tabular}

\subsection{Avaliação da qualidade de sono e da capacidade para realização de atividades rotineiras diárias}

A Tabela 4 descreve a qualidade do sono quantificada pelo paciente através da ENSono $(0-10 \mathrm{~cm})$ e a capacidade de realizar atividades rotineiras diárias quantificadas pela ENCap de 0-10 cm, durante o período de analgesia adequada (END $<4 \mathrm{~cm})$ e inadequada $($ END $\geq 4 \mathrm{~cm})$, após as sequências de bloqueios ou após RF.

Durante o período de analgesia referido pelos pacientes (em média 5 meses após sequência de 4 bloqueios e 15 meses após RF), a qualidade de sono foi descrita pela totalidade dos pacientes (24/24) como sono adequado e reconfortante, sendo quantificado pela ENSono 0-10 cm $(p<0,001)$. Na analgesia adequada a média de avaliação do sono foi de 2,92 $\pm 0,97$, significativamente melhor do que no período de analgesia inadequada em que a média foi de $6,21 \pm 1,84(p<0,001)$ (Tabela 4). Os pacientes submetidos à sequência de 4 bloqueios relataram diminuição do sono nas duas ou três primeiras noites após cada procedimento realizado, porém sem resultar em cansaço diurno.

A capacidade de realizar atividades físicas rotineiras também demonstrou diferença significativa entre os períodos analisados $(p<0,05)$. Segundo os dados obtidos, os pacientes sentiram-se mais capazes de realizar essas atividades no período de analgesia adequada do que na analgesia inadequada $(3,5 \pm 0,98$ e $6,38 \pm 1,71$, respectivamente) (Tabela 4$)$. 
Figura 11 - Capacidade para realização de atividades rotineiras durante os períodos de analgesia inadequada $(E N D \geq 4)$ e adequada $(E N D<4)$. Cada ícone representa um paciente, a linha representa a média dos pacientes e as barras o desvio padrão $(n=24$ pacientes $)$

\section{Capacidade de realizar atividades}

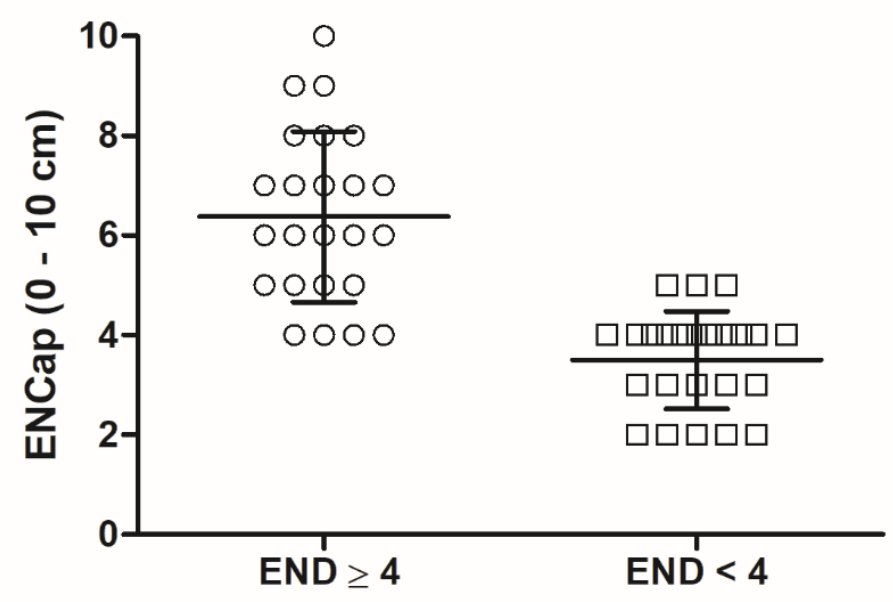

\subsection{Avaliação do custo anual gasto para controle da dor nos pacientes portadores de} SDCR-I

Para esse cálculo foi considerada a média de internações descritas, i.e., para a técnica convencional de sequência de bloqueios foram considerados quatro bloqueios semestrais, perfazendo o total de oito bloqueios por ano. Para o bloqueio teste seguido da realização da RF, o custo foi calculado para uma internação por ano, considerando a duração média de 15 meses de analgesia adequada após intervenção única por essa técnica.

\subsection{Custos anuais}

\subsubsection{Custos anuais com sequência de 4 bloqueios}

Considerando os dados referentes à última atualização, realizada em maio de 2020, cada internação para a realização do bloqueio neurolítico simpático e do bloqueio neuropático representa para o SUS um ônus no valor de R \$ 1.516,18 para o "Tratamento de lesão do sistema neurovegetativo por agentes químicos" (que corresponde ao bloqueio autonômico), e de R\$ 382,12 para "neurólise não funcional de nervos periféricos" (que correspondente ao bloqueio neuropático) (Quadro 2). 
O custo anual por paciente seria de R \$ 15.186,40, sem incluir neste cálculo:

- $\quad$ mão de obra especializada em cada internação;

- $\quad$ estadia na sala de recuperação anestésica;

- $\quad$ uso da sala cirúrgica;

- $\quad$ uso do intensificador de imagem;

- $\quad$ mobilização do paciente de sua casa para o hospital (gasto individual).

Quadro 2 - Custo anual de sequência de 4 bloqueios (Grupo 1) por paciente portador da SDCRI

\begin{tabular}{|c|c|c|}
\hline Descrição do item & $\begin{array}{c}\text { Valor unitário por } \\
\text { paciente e por } \\
\text { bloqueio }^{\mathbf{a}}\end{array}$ & $\begin{array}{c}\text { Valor anual por paciente } \\
\text { (8 bloqueios, } 4 \text { por } \\
\text { semestre) }\end{array}$ \\
\hline $\begin{array}{l}\text { "Tratamento de lesão do sistema } \\
\text { neurovegetativo por agentes } \\
\text { químicos" (Porte Tabela } \\
\text { SIGTAP-SUS) (corresponde ao } \\
\text { bloqueio autonômico) }\end{array}$ & $\mathrm{R} \$ 1.516,18$ & $\mathrm{R} \$ 12.129,44$ \\
\hline $\begin{array}{l}\text { "Neurólise não funcional de } \\
\text { nervos periféricos" para bloqueio } \\
\text { de nervo periférico(fonte } \\
\text { SIGTAP-SUS) (corresponde ao } \\
\text { bloqueio neuropático) }\end{array}$ & $\mathrm{R} \$ 382,12$ & $\mathrm{R} \$ 3.056,96$ \\
\hline TOTAL & RS 1.898,30 & R\$ 15.186,40 \\
\hline
\end{tabular}

${ }^{a}$ Dados do Sistema Único de Saúde (SUS) referentes ao ano de 2020.

\subsubsection{Custos anuais com RF}

A técnica por ablação por RF, para controle da mesma patologia, custou o valor de $\mathrm{R} \$$ 11.210,22 por ano/paciente, no primeiro ano de tratamento (Quadro 3).

Apenas no primeiro ano, se faz necessário a realização de um bloqueio teste, perfazendo o valor R\$1.898,30 de gastos ao SUS pela internação. Nos anos subsequentes, esse valor deve ser deduzido do custo anual. Para cada paciente é utilizado por internação um conjunto de agulhas de RF por internação no valor de R\$ 9.500,00, que corresponde ao montante inserido no cálculo do custo da técnica de RF nos anos subsequentes. 
Quadro 3 - Custo anual de bloqueio teste seguido de ablação por RF (Grupo 2) por paciente portador de SDCR-I

\begin{tabular}{|c|c|c|}
\hline Descrição do item & $\begin{array}{c}\text { Valor unitário por } \\
\text { paciente }^{\text {a }}\end{array}$ & $\begin{array}{l}\text { Valor anual por paciente } \\
\text { ( } 1 \text { bloqueios teste e RF) }^{b}\end{array}$ \\
\hline 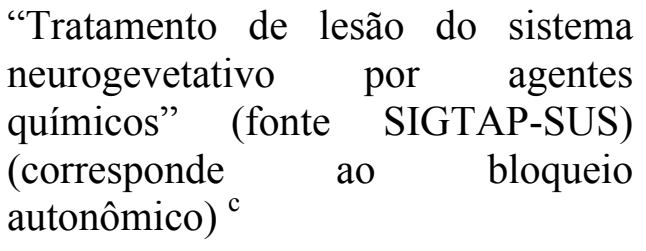 & $\mathrm{R} \$ 1.516,18$ & $\mathrm{R} \$ 1.516,18$ \\
\hline $\begin{array}{l}\text { "Neurólise não funcional de nervos } \\
\text { periféricos" para bloqueio de nervo } \\
\text { periférico(fonte } \\
\text { (corresponde } \\
\text { neuropático) }\end{array}$ & $\mathrm{R} \$ 382,12$ & $\mathrm{R} \$ 382,12$ \\
\hline Conjunto de agulhas de RF & $\mathrm{R} \$ 9.500,00$ & $\mathrm{R} \$ 9.500,00$ \\
\hline TOTAL & R\$ 11.398,30 & R\$ 11.398,30 \\
\hline
\end{tabular}

\subsubsection{Extrapolação dos custos ao longo dos anos e economia por paciente}

De acordo com os dados do IBGE, a esperança de vida projetada para a população do Brasil para o Período 2000/2060, calculada após o último censo realizado em 2014, para ambos os sexos é de 75,1 anos e, especificamente para o estado de São Paulo, é de 77,5 anos. (73) A média de idade dos pacientes do presente estudo foi de 46,04 anos. Dessa forma, por se tratar de uma doença crônica, extrapolamos os cálculos de custos para os próximos 30 anos baseados nos valores atuais para obter uma estimativa da economia por paciente durante todo o seu tratamento.

A economia observada por paciente aumenta progressivamente começando em $24,94 \%$ e chegando a 37,03\% em 30 anos (Tabela 5). Os dados dos primeiros cinco anos estão representados na Figura 12 e dos anos subsequentes na Figura 13. 
Tabela 5 - Custo e economia anual por paciente considerando os diferentes esquemas de tratamento, 4 bloqueios ou radiofrequência (RF) no período de 1 ano, extrapolado para demais anos de tratamento

\begin{tabular}{ccccc}
\hline $\begin{array}{c}\text { Tempo de tratamento } \\
\text { por paciente (anos) }\end{array}$ & $\begin{array}{c}\text { Custo no período } \\
\text { (4 bloqueios) }\end{array}$ & $\begin{array}{c}\text { Custo no } \\
\text { período }(\mathrm{RF})\end{array}$ & $\begin{array}{c}\text { Economia no período } \\
\text { por paciente }\end{array}$ & $\begin{array}{c}\text { \% de Economia } \\
\text { por paciente }\end{array}$ \\
\hline 1 & $\mathrm{R} \$ 15.186,40$ & $\mathrm{R} \$ 11.398,30$ & $\mathrm{R} \$ 3.788,10$ & 24,94 \\
2 & $\mathrm{R} \$ 30.372,80$ & $\mathrm{R} \$ 20.898,30$ & $\mathrm{R} \$ 9.474,50$ & 31,19 \\
3 & $\mathrm{R} \$ 45.559,20$ & $\mathrm{R} \$ 30.398,30$ & $\mathrm{R} \$ 15.160,90$ & 33,28 \\
4 & $\mathrm{R} \$ 60.745,60$ & $\mathrm{R} \$ 39.898,30$ & $\mathrm{R} \$ 20.847,30$ & 34,32 \\
5 & $\mathrm{R} \$ 75.932,00$ & $\mathrm{R} \$ 49.398,30$ & $\mathrm{R} \$ 26.533,70$ & 34,94 \\
10 & $\mathrm{R} \$ 151.864,00$ & $\mathrm{R} \$ 96.898,30$ & $\mathrm{R} \$ 54.965,70$ & 36,19 \\
15 & $\mathrm{R} \$ 227.796,00$ & $\mathrm{R} \$ 144.398,30$ & $\mathrm{R} \$ 83.397,70$ & 36,61 \\
20 & $\mathrm{R} \$ 303.728,00$ & $\mathrm{R} \$ 191.898,30$ & $\mathrm{R} \$ 111.829,70$ & 36,82 \\
25 & $\mathrm{R} \$ 379.660,00$ & $\mathrm{R} \$ 239.398,30$ & $\mathrm{R} \$ 140.261,70$ & 36,94 \\
30 & $\mathrm{R} \$ 455.592,00$ & $\mathrm{R} \$ 286.898,30$ & $\mathrm{R} \$ 168.693,70$ & 37,03 \\
\hline
\end{tabular}

Figura 12 - Custo anual estimados por pacientes utilizando a técnica de 4 bloqueios ou radiofrequência (RF) com extrapolação para o período de 5 (cinco) anos. A porcentagem (\%) indica a economia por paciente, em cada período, utilizando a RF em relação à técnica de 4 bloqueios

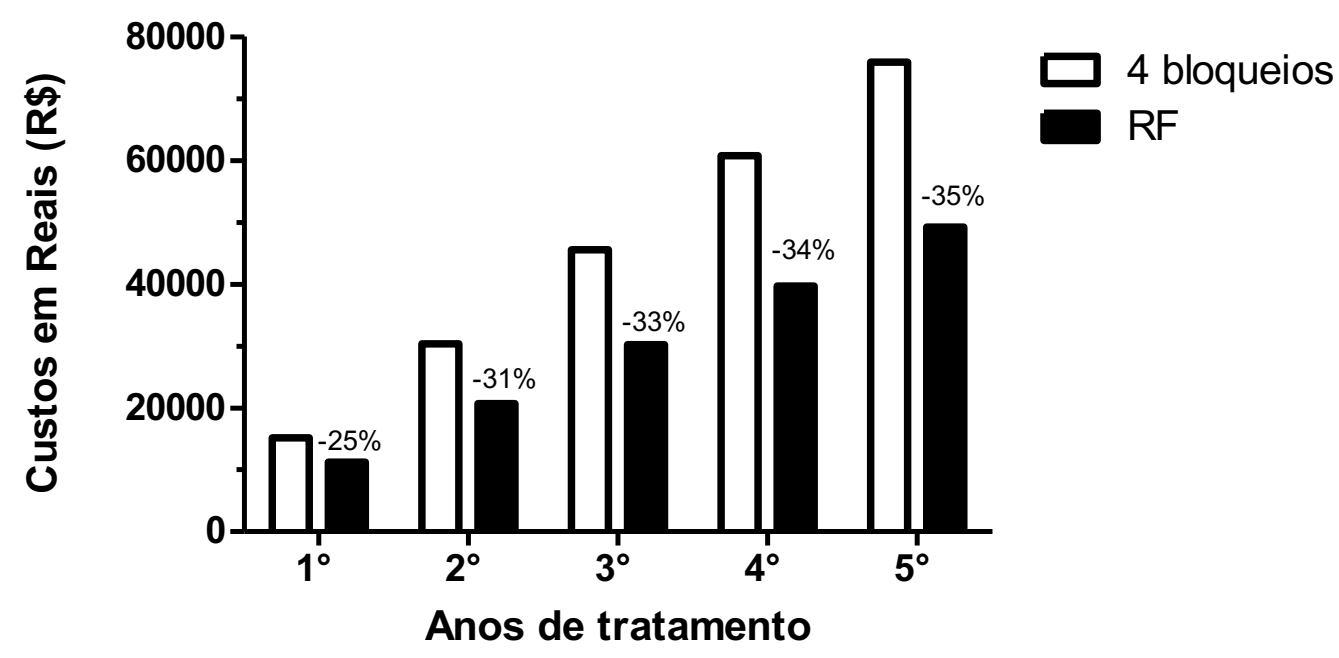


Figura 13 - Custo anual estimados por pacientes utilizando a técnica de 4 bloqueios ou radiofrequência (RF) com extrapolação para o período de 15 (quinze) anos. A porcentagem (\%) indica a economia por paciente, em cada período, utilizando a RF em relação à técnica de 4 bloqueios

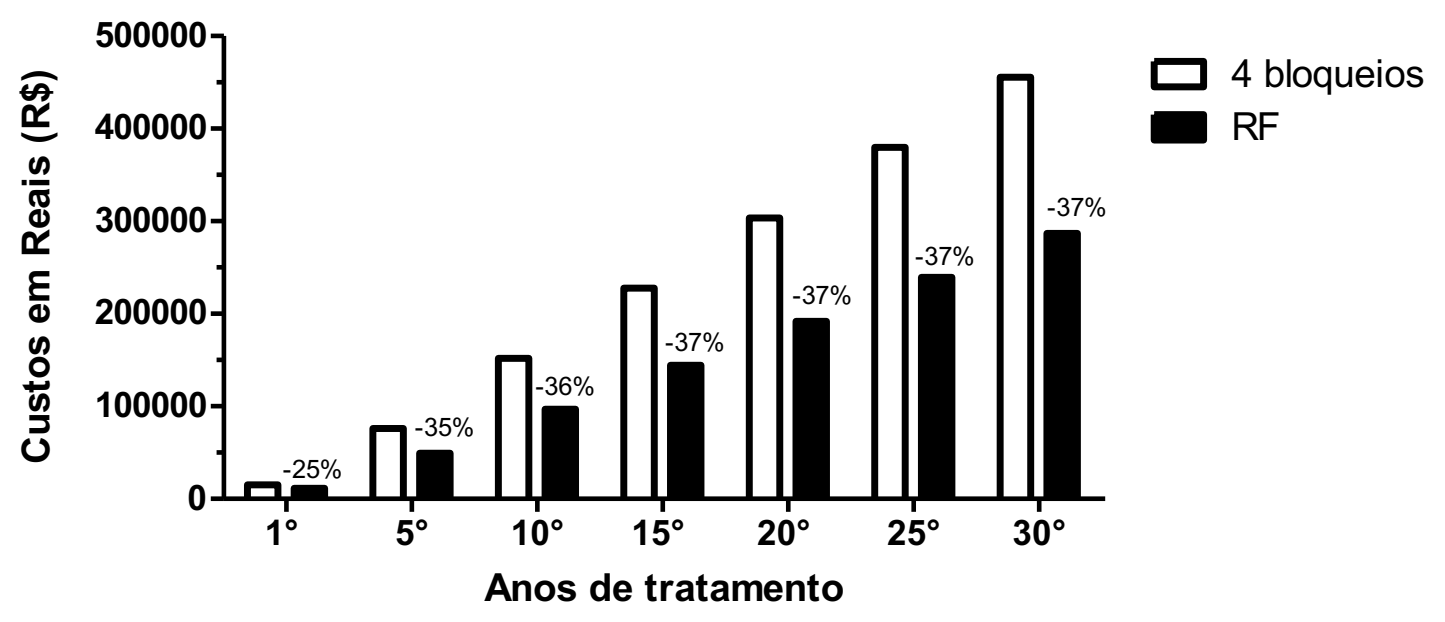

\subsection{Avaliação dos efeitos adversos}

Durante as duas fases do estudo os pacientes não relataram efeitos adversos extras aos que já sentiam com o uso dos fármacos rotineiros (anticonvulsivante, antidepressivo e metadona). Ou seja, tanto a realização de quatro sequências de bloqueios quanto a realização da RF não resultaram em efeitos adversos importantes.

Os pacientes não referiram quaisquer indisposição gástrica quando foram submetidos a bloqueio teste, seguidos de quatro sequências de bloqueios semanais, ou quando foram submetidos a bloqueio teste seguido de RF. 


\section{DISCUSSÃO}

Não existe um protocolo padrão preconizado para o tratamento da SDCR-I, uma doença crônica e complexa. No presente estudo, foi demonstrado que na SDCR-I o tempo de analgesia foi três vezes maior (15 meses) quando realizada a ablação por RF dos gânglios simpáticos L3L4-L5 associados à modulação gânglio de raiz dorsal (DRG) L3-L4-L5, em comparação aos bloqueios clássicos quinzenais. Além disso, na RF observou-se uma melhor capacidade para realizar atividades físicas de rotina, melhor padrão de sono e, em média, 30\% de redução nos custos anuais por paciente. Conforme descrito, mantivemos toda a polifarmácia durante a condução do estudo. No entanto, $17 \%$ dos pacientes eram refratários ao tratamento medicamentoso e se beneficiaram do implante de eletrodo de estimulação medular. Não foi possível comparar essa incidência de insucesso com outras publicações, pois faltam dados na literatura relacionados à incidência de falha do bloqueio teste na SDRC-1.

Enquanto o tratamento 1 incluiu bloqueio peridural sacral, o tratamento 2 incluiu modulação por RF do DRG da região afetada (L3-L4-L5), procedimentos utilizados para reverter a sensibilização central à dor. A sensibilização central é parcialmente explicada pela hiper excitabilidade do DRG, demonstrada na SDCR. As células gliais perineurais do DRG produzem diversos mediadores pró-inflamatórios, incluindo IL-1 $\beta$ derivada de micróglia. (74) Além disso, a micróglia que expressa o receptor canabinóide-2 e o receptor de quimiocina fractalina (CX3CR1) desempenha um papel substancial na ativação microglial e na neuroinflamação. (75)

A indução da adenosina espinhal também pode participar dessa hiper excitabilidade que tem como consequência uma resposta imune tanto rostral quanto caudal em relação ao GRD, e em outros locais da medula espinhal, explicando o desenvolvimento de dor generalizada e disfunção autonômica. $(76,77)$

De maneira geral, são os mecanismos inflamatórios que ativam a sensibilização central à dor (78). O processo inflamatório que contribui para a SDCR especificamente resulta de duas sequências inflamatórias. Em primeiro lugar, os mecanismos inflamatórios clássicos através das células imunológicas. Após o trauma, tecidos moles, mastócitos e linfócitos liberam citocinas pró-inflamatórias, incluindo TNF- $\alpha$, IL-1 $\beta$, IL2 e IL-6. (79) Em segundo lugar, mecanismos de inflamação neurogênica, por meio da liberação direta de mediadores de neuropeptídeos (peptídeo relacionado ao gene da calcitonina, substância P e bradicinina) e citocinas inflamatórias das fibras nociceptivas (80). Ambas as cascatas inflamatórias ativam a sensibilização central. (78) Além disso, a expressão de receptores adrenérgicos nas fibras 
nociceptivas, após dano tecidual, pode induzir dor de característica autonômica simpática em pacientes com SDRC. (81) Por fim, existe um mecanismo compensatório de up-regulation nos receptores adrenérgicos periféricos que pode levar a uma maior sensibilidade às catecolaminas circulantes. (82)

O sucesso do tratamento da SDRC envolvendo o membro inferior foi descrito após a utilização de bupivacaína peridural contínua, (83) dando um papel de relevância para os anestésicos locais peridurais na sensibilização central à dor. No presente estudo, para o bloqueio sacral epidural, foi utilizado lidocaína na dose de $40 \mathrm{mg}$. No entanto, a eficácia dessa dose baixa pode ser devido ao fato de o DRG ser o alvo principal de intervenção para controle ectópico de dor e sensação de alodinia. Dessa forma, o DRG foi seletivamente suprimido pela lidocaína em concentrações suficientemente baixas para bloquear apenas o impulso propagatório axonal, sem, entretanto, fazer bloqueio sensitivo ou da função motora, como já descrito por Yatziv e Devor. (84)

Além da lidocaína, a dexametasona foi o esteróide não particulado de escolha, (85) e a combinação de clonidina e dexametasona, para injeção peridural, não formou precipitados de partículas menores não-agregadas em comparação com a dexametasona isoladamente, provando ser uma combinação útil, como já descrito por Gazelka et al. (86)

Em ratos, já foi descrito que a dexametasona reverte a sensibilização central e a hiperalgesia induzidas pelo L-glutamato e substância P, através de uma ação dependente dos óxidos nítricos dos mensageiros intracelulares, ácido araquidônico e proteína C Kinase. (87) Por sua vez, a clonidina perineural reduz a expressão de citocinas locais por ações nos adrenoceptores alfa2, com hipersensibilidade reduzida na lesão nervosa estabelecida, provavelmente por um mecanismo imunomodulador. (88) O efeito neuroprotetor da clonidina durante a isquemia pode ser atribuído tanto à sensibilização da atividade simpática central quanto à liberação reduzida de glutamato, reduzindo assim a ativação do receptor NMDA. (89)

No presente estudo, os pacientes submetidos ao Tratamento 1 receberam a quantidade total de $360 \mathrm{mg}$ de lidocaína, $30 \mathrm{mg}$ de dexametasona e $75 \mathrm{mcg}$ de clonidina; enquanto no Tratamento 2 eles receberam a quantidade total de $200 \mathrm{mg}$ de lidocaína, $30 \mathrm{mg}$ de dexametasona e 75 mcg de clonidina. No entanto, o tempo decorrido até que cada paciente fosse cruzado para o tratamento seguinte era sempre superior a três meses (3-8 meses; mínimo-máximo), o que seria suficiente para evitar qualquer ação sistêmica da lidocaína (90) ou clonidina. (91) Consequentemente, os resultados obtidos no presente estudo implicam que todos os benefícios da analgesia observados foram secundários à ação central de cada bloqueio ou tratamento por RF. 
Em relação à qualidade de vida, a técnica de intervenção a cada duas semanas (14 dias) resultou em analgesia de cinco meses, enquanto a RF resultou em analgesia de 15 meses, acompanhada de maior capacidade de atividades diárias e melhor padrão de sono, o que certamente refletiu em uma melhor qualidade de vida durante o período de analgesia controlada, como observado também por Mouraux et al., (92) além de uma lista de espera reduzida para tratamento. Imani et al. (93) descreveram de cinco a seis meses de analgesia após bloqueio de gânglio estrelado na SDRC, o que seria semelhante aos nossos achados na sequência clássica de bloqueios dos gânglios simpáticos, porém nas extremidades inferiores. Em nosso estudo, a modulação de RF da DRG combinada à ablação clássica de gânglios simpáticos nos mesmos níveis (L3-L4-L5) resultou em analgesia de 15 meses. Considerando as limitações do presente estudo, destacamos a possibilidade de incluir um terceiro grupo de estudos, em que os pacientes seriam submetidos somente à ablação clássica dos gânglios simpáticos L3-L4-L5. Entretanto, no delineamento experimental original a intenção não era de fazer um estudo triplo tipo crossmatch e, também, não seria possível realizar três grupos independentes duplo-cegos, o que poderia ser considerado como um viés.

O tratamento tradicional de 4 semanas para o SDCR-I foi aplicado tendo, por consequência, de oito a nove internações por ano, o que significa mais despesas pessoais, além dos custos do Sistema Público de Saúde contabilizados no presente estudo. Além do benefício de uma única internação no período de um ano, a técnica de RF apresenta menor custo hospitalar, resultando em redução dos gastos por paciente no período de um ano e nos anos subsequentes. É importante ressaltar que a redução nos custos contabilizados para a técnica de RF foi observada desde o primeiro ano de tratamento. Outra vantagem na redução do número de internações, caso a RF fosse adotada como parte do tratamento, é a oportunidade de um número maior de pacientes serem tratados. 


\section{CONCLUSÕES}

O tempo de analgesia para pacientes portadores de SDCR-I, quando submetidos à sequência de bloqueio teste seguida por realização de sequência de 4 bloqueios semanais do sistema simpático autônomo acometido e associado ao bloqueio peridural sacral, foi três vezes menor do que quando os mesmos pacientes foram submetidos ao bloqueio teste seguido de ablação por RF dos gânglios simpáticos de L3, L4 e L5, associados à modulação por RF dos gânglios dorsais de L3, L4 e L5. Entretanto, o consumo de analgésicos de resgate foi semelhante entre os dois grupos durante o período de analgesia adequado em cada grupo. Durante esse período, o padrão de sono e a capacidade para a realização de atividades rotineiras foram adequadas para todos os pacientes do estudo, refletindo em melhor qualidade de vida. O número médio de internações anuais para o Grupo 1 foi extrapolado para oito internações por ano/paciente, enquanto para o Grupo 2 foi extrapolado para 1-2 por ano/paciente.

$\mathrm{O}$ custo financeiro dos pacientes submetidos ao bloqueio teste seguido por RF apresentou economia anual variando de $25 \%$ a $37 \%$ durante a avaliação no tempo da doença, considerando o menor número médio de internações por ano, em comparação à técnica rotineiramente adotada de quatro bloqueios.

Sendo assim, podemos concluir que a técnica de RF dos mesmos níveis para ablação simpática e modulação do DRG (L3-L4-L5) foi econômica e resultou em tempo de analgesia significativamente superior quando comparada à sequência tradicional de quatro bloqueios. Os dados sugerem, portanto, que o tratamento da sensibilização central à dor deve ser considerado nessa população do estudo. 


\section{REFERÊNCIAS}

1. Petersen PB, Mikkelsen KL, Lauritzen JB, Krogsgaard MR. Risk factors for post-treatment complex regional pain syndrome (CRPS): an analysis of 647 cases of CRPS from the Danish Patient Compensation Association. Pain Pract. 2018;18(3):341-9. doi: 10.1111/papr.12610

2. Misidou C, Papagoras C. Complex regional pain syndrome: an update. Mediterr J Rheumatol. 2019;30(1):16-25. doi: 10.31138/mjr.30.1.16

3. Shim H, Rose J, Halle S, Shekane P. Complex regional pain syndrome: a narrative review for the practising clinician. $\mathrm{Br} \mathrm{J}$ Anaesth. 2019;123(2):e424-e433. doi: 10.1016/j.bja.2019.03.030

4. Harden RN, Bruehl S, Stanton-Hicks M, Wilson PR. Proposed new diagnostic criteria for complex regional pain syndrome. Pain Med. 2007;8(4):326-31.

5. Kumar KH, Elavarasi P. Definition of pain and classification of pain disorders. J Adv Clin Res Insights. 2016;3:87-90. doi: 10.15713/ins.jcri.112

6. Feliu MH, Edwards CL. Psychologic factors in the development of complex regional pain syndrome: history, myth, and evidence. Clin J Pain. 2010;26(3):258-63. doi: 10.1097/AJP.0b013e3181bff815

7. de Rooij AM, Florencia Gosso M, Haasnoot GW. HLA-B62 and HLA-DQ8 are associated with Complex Regional Pain Syndrome with fixed dystonia. Pain. 2009;145(1-2):82-5. doi: 10.1016/j.pain.2009.05.015

8. Jin EH, Zhang E, Ko Y. Genome-wide expression profiling of complex regional pain syndrome. PLoS One. 2013;8(11):e79435. doi: 10.1371/journal.pone.0079435

9. Orlova IA, Alexander GM, Qureshi RA. MicroRNA modulation in complex regional pain syndrome. J Transl Med. 2011;9:195. doi: 10.1186/1479-5876-9-195 
10. Janicki PK, Alexander GM, Eckert J, Postula M, Schwartzman RJ. Analysis of common single nucleotide polymorphisms in complex regional pain syndrome: genome wide association study approach and pooled DNA strategy. Pain Med. 2016;17(12):2344-52. doi: $10.1093 / \mathrm{pm} / \mathrm{pnw} 133$

11. Ott S, Maihofner C. Signs and symptoms in 1,043 patients with complex regional pain syndrome. J Pain. 2018;19(6):599-611. doi: 10.1016/j.jpain.2018.01.004

12. Kim H, Lee CH, Kim SH, Kim YD. Epidemiology of complex regional pain syndrome in Korea: an electronic population health data study. PLoS One. 2018;13(6):e0198147. doi: 10.1371/journal.pone.0198147

13. Sandroni P, Benrud-Larson LM, McClelland RL, Low PA. Complex regional pain syndrome type I: incidence and prevalence in Olmsted county, a population-based study. Pain. 2003;103(1-2):199-207. doi: 10.1016/s0304-3959(03)00065-4

14. Avdic D, Jaganjac A, Katana B, Bojicic S, Hadziomerovic AM, Svraka E. Complex regional pain syndrome (CRPS). J Health Sci. 2015;5(1):1-4. doi: 10.17532/jhsci.2015.240

15. Bruehl S. Complex regional pain syndrome. BMJ. 2015;351:h2730. doi: 10.1136/bmj.h2730

16. Neumeister MW, Romanelli MR. Complex Regional Pain Syndrome. Clin Plast Surg. 2020;47(2):305-10. doi: 10.1016/j.cps.2019.12.009

17. Ghai B, Dureja G. Complex regional pain syndrome: a review. J Postgrad Med. 2004;50(4):300-7.

18. Merskey H, Bogduk N. Classification of chronic pain: descriptions of chronic pain syndromes and definition of terms. Seattle: IASP Press; 1994.

19. Urits I, Shen AH, Jones MR, Viswanath O, Kaye AD. Complex regional pain syndrome, current concepts and treatment options. Curr Pain Headache Rep. 2018;22(2):10. doi: $10.1007 / \mathrm{s} 11916-018-0667-7$ 
20. Harden R, Bruehl S. Diagnostic criteria: the statistical derivation of the four criterion factors. In: Wilson PR, Stanton-Hicks M, Harden RN. CRPS: current diagnosis and therapy. Seattle: IASP Press; 2005. p. 45-58.

21. Harden RN, Bruehl S, Perez RS, Birklein F, Marinus J, Maihofner C, et al. Validation of proposed diagnostic criteria (the "Budapest Criteria") for complex regional pain syndrome. Pain. 2010;150(2):268-74. doi: 10.1016/j.pain.2010.04.030

22. Smart KM, Wand BM, O'Connell NE. Physiotherapy for pain and disability in adults with complex regional pain syndrome (CRPS) types I and II. Cochrane Database Syst Rev. 2016;2:CD010853. doi: 10.1002/14651858.CD010853.pub2

23. Böger A. How to treat complex regional pain syndrome (CRPS). MMW Fortschr Med. 2020;162(1):52-6. doi: 10.1007/s15006-020-0061-3

24. Brown S, Johnston B, Amaria K. A randomized controlled trial of amitriptyline versus gabapentin for complex regional pain syndrome type I and neuropathic pain in children. Scand J Pain. 2016;13:156-63. doi: 10.1016/j.sjpain.2016.05.039

25. Harke H, Gretenkort P, Ladleif HU, Rahman S, Harke O. The response of neuropathic pain and pain in complex regional pain syndrome I to carbamazepine and sustained-release morphine in patients pretreated with spinal cord stimulation: a double-blinded randomized study. Anesth Analg. 2001;92(2):488-95. doi: 10.1097/00000539-200102000-00039

26. Breuer AJ, Mainka T, Hansel N, Maier C, Krumova EK. Short-term treatment with parecoxib for complex regional pain syndrome: a randomized, placebo-controlled doubleblind trial. Pain Physician. 2014;17(2):127-37.

27. Kingery WS. A critical review of controlled clinical trials for peripheral neuropathic pain and complex regional pain syndromes. Pain. 1997;73(2):123-39. doi: 10.1016/s03043959(97)00049-3 
28. Kalita J, Misra U, Kumar A, Bhoi SK. Long-term prednisolone in post-stroke complex regional pain syndrome. Pain Physician. 2016;19(8):565-74.

29. Lee JW, Lee SK, Choy WS. Complex Regional Pain Syndrome type 1: diagnosis and management. J Hand Surg Asian Pac Vol. 2018;23(1):1-10. doi: $10.1142 / \mathrm{S} 2424835518300013$

30. Deer TR, Levy RM, Kramer J. Dorsal root ganglion stimulation yielded higher treatment success rate for complex regional pain syndrome and causalgia at 3 and 12 months: a randomized comparative trial. Pain. 2017;158(4):669-81. doi: 10.1097/j.pain.0000000000000814

31. O'Connell NE, Wand BM, Gibson W, Carr DB, Birklein F, Stanton TR. Local anaesthetic sympathetic blockade for complex regional pain syndrome. Cochrane Database Syst Rev. 2016;7:CD004598. doi: 10.1002/14651858.CD004598.pub4

32. Awal S, Madabushi R, Agarwal A, Singla V. CRPS: early lumbar sympathetic block is better compared to other interventions. Pain Physician. 2016;19(2):E363.

33. Datta R, Agrawal J, Sharma A, Rathore VS, Datta S. A study of the efficacy of stellate ganglion blocks in complex regional pain syndromes of the upper body. J Anaesthesiol Clin Pharmacol. 2017;33(4):534-40. doi: 10.4103/joacp.JOACP_326_16

34. Dev S, Yoo Y, Lee HJ, Kim DH, Kim YC, Moon JY. Does temperature increase by sympathetic neurolysis improve pain in complex regional pain syndrome? A retrospective cohort study. World Neurosurg. 2018;109:e783-e791. doi: 10.1016/j.wneu.2017.10.088

35. Zhu X, Kohan LR, Morris JD, Hamill-Ruth RJ. Sympathetic blocks for complex regional pain syndrome: a survey of pain physicians. Reg Anesth Pain Med. 2019;44(7):736-41. doi: 10.1136/rapm-2019-100418

36. Lee Y, Lee CJ, Choi E, Lee PB, Lee HJ, Nahm FS6. Lumbar sympathetic block with botulinum toxin type A and type B for the Complex Regional Pain Syndrome. Toxins (Basel). 2018;10(4):E164. doi: 10.3390/toxins10040164 
37. Van Buyten JP, Smet I, Liem L, Russo M, Huygen F. Stimulation of dorsal root ganglia for the management of complex regional pain syndrome: a prospective case series. Pain Pract. 2015;15(3):208-16. doi: 10.1111/papr.12170

38. Shealy CN. Percutaneous radiofrequency denervation of spinal facets. Treatment for chronic back pain and sciatica. J Neurosurg. 1975;43(4):448-51. doi: 10.3171/jns. 1975.43.4.0448

39. Sluijter ME. The use of radiofrequency lesions for pain relief in failed back patients. Int Disabil Stud. 1988;10(1):37-43. doi: 10.3109/09638288809164058

40. Lord SM, Bogduk N. Radiofrequency procedures in chronic pain. Best Pract Res Clin Anaesthesiol. 2002;16(4):597-617. doi:10.1053/bean.2002.0250

41. Van Kleff M. Radiofrequency lesions adjacent to the dorsal root ganglion [thesis]. Maastricht: Datawyse; 1996.

42. Sluijter ME, Racz G. Technical aspects of radiofrequency. Pain Pract. 2002;2(3):195-200. doi: 10.1046/j.1533-2500.2002.02023.x

43. Racz GB, Ruiz-Lopez R. Radiofrequency procedures. Pain Practice. 2006;6(1):46-50. doi: $10.1111 / \mathrm{j} .1533-2500.2006 .00058 . \mathrm{x}$

44. Kim HS, Wu PH, Jang IT. Lumbar degenerative disease Part 1: Anatomy and pathophysiology of intervertebral discogenic pain and radiofrequency ablation of basivertebral and sinuvertebral nerve treatment for chronic discogenic back pain: a prospective case series and review of literature. Int J Mol Sci. 2020;21(4):E1483. doi: $10.3390 /$ ijms 21041483

45. Vatansever D, Tekin I, Tuglu I, Erbuyun K, Ok G. A comparison of the neuroablative effects of conventional and pulsed radiofrequency techniques. Clin J Pain. 2008;24(8):71724. doi: 10.1097/AJP.0b013e318173c27a 
46. Shealy CN. Electrical stimulation: the primary method of choice in pain relief. Compr Ther. $1975 ; 1(1): 41-5$.

47. Levin JH. Prospective, double-blind, randomized placebo-controlled trials in interventional spine: what the highest quality literature tells us. Spine J. 2009;9(8):690-703. doi: 10.1016/j.spinee.2008.06.447

48. Braun Filho JL, Braun LM. Radiofrequência na dor crônica. Coluna/Columna. 2009;8(2):200-5. doi: 10.1590/S1808-18512009000200017

49. Raus PPM, Verhaert PDEM. Radiofrequency surgery: 3500 years old and still young. Orbit. 2018;37(3):159-64. doi: 10.1080/01676830.2017.1383469

50. Lord SM, Barnsley L, Wallis BJ, McDonald GJ, Bogduk N. Percutaneous radiofrequency neurotomy for chronic cervical zygapophyseal-joint pain. $\mathrm{N}$ Engl $\mathrm{J}$ Med. 1996;335(23):1721-6. doi: 10.1056/NEJM199612053352302

51. Chou R, Atlas SJ, Stanos SP, Rosenquist RW. Nonsurgical interventional therapies for low back pain: a review of the evidence for an American pain society clinical practice guideline. Spine. 2009;34(10):1078-93. doi: 10.1097/BRS.0b013e3181a103b1

52. Zhang JH, Yang CX, Zhong JY, Zhang L, Xiong QM, Wang J, et al. The influence of lumbar sympathetic ganglion radiofrequency thermocoagulation on the activation of microglia in rats with diabetic neuropathic pain. Zhonghua Yi Xue Za Zhi. 2016;96(24):1934-8. doi: 10.3760/cma.j.issn.0376-2491.2016.24.014

53. Bonora M, Wieckowsk MR, Chinopoulos C, Kepp O, Kroemer G, Galluzzi L, et al. Molecular mechanisms of cell death: central implication of ATP synthase in mitochondrial permeability transition. Oncogene. 2015;34(12):1608. doi: 10.1038/onc.2014.462

54. Yamashita K, Ghafoori E, Silvernagel J, Ashton J, J Dosdall D, MacLeod R, et al. The effective contact force to minimize edema relative to chronic lesion formation during radiofrequency ablation in ventricular wall. Int Heart J. 2019;60(6):1407-14. doi: 10.1536/ihj.19-128 
55. Slappendel R, Crul BJ, Braak GJ, Geurts JW, Booij LH, Voeman VF, et al. The efficacy of radio- frequency lesioning of the cervical spinal dorsal root ganglion in a double blind randomized study: no difference between 40 degrees and 67 degrees $\mathrm{C}$ treatments. Pain. 1997;73(2):159-63. doi: 10.1016/s0304-3959(97)00094-8

56. Sluijter ME, Van Kleff M. Characteristics and mode of action of radiofrequency lesions. Curr Rev Pain. 1998;2:143-50. doi: 10.1007/s11916-998-0011-8

57. Chang MC. Efficacy of pulsed radiofrequency stimulation in patients with peripheral neuropathic pain: a narrative review. Pain Physician. 2018;21(3):E225-E234.

58. Vanneste T, Van Lantschoot A, Van Boxem K, Van Zundert J. Pulsed radiofrequency in chronic pain. Curr Opin Anesthesiol. 2017;30(5):577-82. doi: 10.1097/ACO.0000000000000502

59. Van Zundert J, de Louw AJAS, Joosten EAJ. Pulsed and continuous radiofrequency current adjacent to the cervical dorsal root ganglion of the rat induces late cellular activity in the dorsal horn. Anesthesiology. 2005;102(1):125-31. doi: 10.1097/00000542-20050100000021

60. Cosman ER Jr, Cosman ER Sr. Electric and thermal field effects in tissue around radiofrequency electrodes. Pain Med. 2005;6(6):405-24. doi: 10.1111/j.15264637.2005.00076.x

61. Glass CK, Saijo K, Winner B, Marchetto MC, Gage FH. Mechanisms underlying inflammation in neurodegeneration. Cell. 2010;140(6):918-34. doi: 10.1016/j.cell.2010.02.016

62. Ransohoff RM, Cardona AE. The myeloid cells of the central nervous system parenchyma. Nature. 2010;468(7321):253-62. doi: 10.1038/nature09615

63. Rojewska E, Makuch W, Przewlocka B, Mika J. Minocycline prevents dynorphin-induced neurotoxicity during neuropathic pain in rats. Neuropharmacology. 2014;86:301-10. doi: 10.1016/j.neuropharm.2014.08.001 
64. Choi DC, Lee JY, Lim EJ, Baik HH, Oh TH, Yune TY. Inhibition of ROS-induced p38MAPK and ERK activation in microglia by acupuncture relieves neuropathic pain after spinal cord injury in rats. Exp Neurol. 2012;236(2):268-82. doi: 10.1016/j.expneurol.2012.05.014

65. Cho HK, Cho YW, Kim EH, Sluijter ME, Hwang SJ, Ahn SH. Changes in pain behavior and glial activation in the spinal dorsal horn after pulsed radiofrequency current administration to the dorsal root ganglion in a rat model of lumbar disc herniation: Laboratory investigation. J Neurosurg Spine. 2013;19(2):256-63. doi: 10.3171/2013.5.SPINE12731

66. Vallejo R, Tilley DM, Williams J, Labak S, Aliaga L, Benyamin RM. Pulsed radiofrequency modulates pain regulatory gene expression along the nociceptive pathway. Pain Physician. 2013;16(5):E601-E613.

67. Cho HK, Kang JH, Kim SY, Choi MJ, Hwang SJ, Cho YW, et al. Changes in neuroglial activity in multiple spinal segments after caudal epidural pulsed radiofrequency in a rat model of lumbar disc herniation. Pain Physician. 2016;19(8):E1197-E1209.

68. Gallagher RM. Pulsed radiofrequency treatment: what is the evidence of its effectiveness and should it be used in clinical practice. Pain Med. 2006;7(5):408-10. doi: 10.1111/j.15264637.2006.00211.x

69. Sluijter M. Radiofrequency, Part 1: The lumbosacral region. Meggen: FlivoPress; 2001.

70. Van Zundert J, Raj P, Erdine S, Van Kleef M. Application of radiofrequency treatment in practical pain management: state of the art. Pain Practice. 2002;2(3):269-78. doi: 10.1046/j.1533-2500.2002.02036.x

71. Liem L, van Dongen E, Huygen FJ, Staats P, Kramer J. The dorsal root ganglion as a therapeutic target for chronic pain. Reg Anesth Pain Med. 2016;41(4):511-9. doi: 10.1097/AAP.0000000000000408 
72. Grieve S, Llewellyn A, Jones L, Manns S, Glanville V, McCabe CS. Complex regional pain syndrome: an international survey of clinical practice. Eur J Pain. 2019;23(10):1890-903. doi: $10.1002 /$ ejp. 1463

73. Instituto Brasileiro de Geografia e Estatística (IBGE). Projeção da População do Brasil, por Sexo e Idade, para o Período 2000/2060 [Internet]. 2014 [citado 2020 maio]. Disponível em: https://sidra.ibge.gov.br/tabela/1174\#resultado

74. Helyes Z, Tékus V, Szentes N, Pohóczky K, Botz B, Kiss T, et al. Transfer of complex regional pain syndrome to mice via human autoantibodies is mediated by interleukin- 1induced mechanisms. Proc Natl Acad Sci USA. 2019;116(26):13067-76. doi: $10.1073 /$ pnas. 1820168116

75. Xu J, Tang Y, Xie M, Bie B, Wu J, Yang H, et al. Activation of cannabinoid receptor 2 attenuates mechanical allodynia and neuroinflammatory responses in a chronic postischemic pain model of complex regional pain syndrome type I in rats. Eur J Neurosci. 2016;44(12):3046-55. doi: 10.1111/ejn.13414

76. Roldan CJ, Lo TC, Huh B. Recurrence of complex regional pain syndrome after administration of adenosine. Pain Manag. 2019;9(3):233-7. doi: 10.2217/pmt-2018-0059

77. Martínez-Lavín M, Vargas A, Silveira LH, Amezcua-Guerra LM, Martínez-Martínez LA, Pineda C. Complex Regional Pain Syndrome evolving to full-blown fibromyalgia: a proposal of common mechanisms. J Clin Rheumatol. 2020 Feb 5. doi: 10.1097/RHU.0000000000001304. [ahead of print].

78. Eldufani J, Elahmer N, Blaiseb G. A medical mystery of complex regional pain syndrome. Heliyon. 2020;6(2):e03329. doi: 10.1016/j.heliyon.2020.e03329

79. Cheng JK, Ji RR. Intracellular signaling in primary sensory neurons and persistent pain. Neurochem Res. 2008;33(10):1970-8. doi: 10.1007/s11064-008-9711-z 
80. Birklein F, Schmelz M. Neuropeptides, neurogenic inflammation and complex regional pain syndrome (CRPS). Neurosci Lett. 2008;437(3):199-202. doi: 10.1016/j.neulet.2008.03.081

81. Bruehl S. An update on the pathophysiology of complex regional pain syndrome. Anesthesiology. 2010;113(3):713-25. doi: 10.1097/ALN.0b013e3181e3db38

82. Schlereth T, Drummond PD, Birklein F. Inflammation in CRPS: role of the sympathetic supply. Auton Neurosci. 2014;182:102-7. doi: 10.1016/j.autneu.2013.12.011

83. Zyluk A, Puchalski P. Successful treatment of paediatric lower limb CRPS by continuous epidural anaesthesia: a report of 2 cases. Handchir Mikrochir Plast Chir. 2018;50(5):359-62. doi: $10.1055 / \mathrm{a}-0747-6127$

84. Yatziv SL, Devor M. Suppression of neuropathic pain by selective silencing of dorsal root ganglion ectopia using nonblocking concentrations of lidocaine. Pain. 2019;160(9):2105-14. doi: $10.1097 /$ j.pain.0000000000001602

85. Derby R, Lee SH, Date ES, Lee JH, Lee CH. Size and aggregation of corticosteroids used for epidural injections. Pain Med. 2008;9(2):227-34. doi: 10.1111/j.15264637.2007.00341.x

86. Gazelka HM, Burgher AH, Huntoon MA, Mantilla CB, Hoelzer BC. Determination of the particulate size and aggregation of clonidine and corticosteroids for epidural steroid injection. Pain Physician. 2012;15(1):87-93.

87. Coderre TJ, Yashpal K. Intracellular messengers contributing to persistent nociception and hyperalgesia induced by L-glutamate and substance $\mathrm{P}$ in the rat formalin pain model. Eur $\mathrm{J}$ Neurosci. 1994;6(8):1328-34. doi: 10.1111/j.1460-9568.1994.tb00323.x

88. Romero-Sandoval A, Eisenach JC. Perineural clonidine reduces mechanical hypersensitivity and cytokine production in established nerve injury. Anesthesiology. 2006;104(2):351-5. doi: 10.1097/00000542-200602000-00022 
89. Ellish WS, Murdoch J, Kindel G, Zhang X, White FA. The effect of clonidine on cell survival, glutamate, and aspartate release in normo- and hyperglycemic rats after near complete forebrain ischemia. Exp Brain Res. 2005;167(4):526-34. doi: 10.1007/s00221005-0064-4

90. Beaussier M, Delbos A, Maurice-Szamburski A, Ecoffey C, Mercadal L. Perioperative use of intravenous lidocaine. Drugs. 2018;78(12):1229-46. doi: 10.1007/s40265-018-0955-x

91. Nielsen BN, Anderson BJ, Falcon L, Henneberg SW, Lauritsen T, Lomstein E, et al. Pharmacokinetics of na intravenous bolus dose of clonidine in children undergoing surgery. Paediatr Anaesth. 2020 Mar 13. doi: 10.1111/pan.13856. [ahead of print].

92. Mouraux D, Lenoir C, Tuna T, Brassinne E, Sobczak S. The long-term effect of complex regional pain syndrome type 1 on disability and quality of life after foot injury. Disabil Rehabil. 2019 Aug 14. doi: 10.1080/09638288.2019.1650295. [ahead of print].

93. Imani F, Hemati K, Rahimzadeh P, Kazemi MR, Hejazian K. Effectiveness of stellate ganglion block under fuoroscopy or ultrasound guidance in upper extremity CRPS. J Clin Diagn Res. 2016;10(1):UC09-12. doi: 10.7860/JCDR/2016/14476.7035 


\author{
ANEXO A \\ Termo de Consentimento Livre e Esclarecido
}

Folha 1 de 3

Termo de Consentimento Livre e Esclarecido

Eu, abaixo assinado, concordo em fazer parte da pesquisa que se chama: "Avaliação do efeito antinociceptivo da ablação neuropática e autonômica por radiofrequência em pacientes portadores de dor crônica Síndrome Dolorosa Complexa Regional do Tipo-I (Dor Lombar) ", ou seja, aqueles pacientes com dor na coluna, no pescoço ou cabeça, com formigamento, e que vai perdendo a força, sente muita dor. Entendi que só participo se quiser, não sou obrigado a participar da pesquisa, não vou ser prejudicado se não quiser participar, e vou ser tratado para a dor da coluna, também. Sei que posso também desistir de participar da pesquisa quando quiser, e que isto não vai me prejudicar, pois serei tratado de qualquer forma. Sei que não serei identificado de forma nenhuma, e que ninguém poderá me reconhecer, pois existe o segredo da minha identidade que é garantido.

Durante todo o tempo que eu estiver participando da pesquisa, sempre que quiser saber qualquer coisa, ou informação sobre o que está ocorrendo, tudo será explicado, e se alguma coisa nova acontecer e eu não gostar, posso desistir sem prejuízo para mim.

Fui esclarecido que serei acompanhado durante todo do o período que for necessário, e mesmo depois que a pesquisa terminar, continuarei recebendo tratamento para minha dor no braço. Sei que a médica responsável é a Dra. Gabriela Rocha Lauretti (Dra. Gabriela da Dor), e ela ficará responsável pelo meu tratamento e seguimento. Qualquer dúvida, posso entrar em contato com ela pelo telefone (016) 91766266.

Não terei despesas durante este tratamento, pois os remédios vão ser fornecidos pela Dra. Gabriela da Dor. Qualquer problema que ocorra devido à participação nesta pesquisa, será resolvido (indenizado) pela Dra. Gabriela da Dor. Não tem nenhuma indústria que participa da pesquisa, é uma pesquisa que a é feita na Clínica de Dor do Hospital das Clínicas. fim da folha 1 


\section{Folha 2 de 3}

\section{Esclarecimentos sobre a pesquisa}

\section{Descrição dos pacientes que podem participar desta pesquisa e qual o procedimento realizado habitualmente}

1. Podem participar da pesquisa pacientes com dor crônica na coluna, com dor crônica na cabeça ou com dor crônica no pescoço e braço. A dor é do tipo cansada, com sensação de queimação, associada a dor tipo choque. Ou com sensação de diminuição da força da perna, queixa de estar caindo à toa, tropeçando. Normalmente, estes pacientes com dor crônica têm dois tipos de nervinhos machucados, e a gente chama de: 1) lesão neuropática, e 2) lesão simpática ou autonômica. Para tratar a dor como um todo, é preciso jogar o remédio direto nos dois tipos de nervos que estão doentes ou seja, funcionando mal. Normalmente, o que realizamos é bloqueios para jogar remédio nos dois tipos de nervos, uma vez por semana, por 4 semanas repetidas (consecutivas), e repetimos todo este tratamento uma vez a cada 4 meses, para tentar controlar a dor e diminuir o quanto de remédio o paciente toma todo o dia. Normalmente usamos no bloqueio que é feito de rotina para tratar a dos na coluna uma mistura de três remédios, que são postos numa mesma seringa e injetados próximo aos nervinhos que estão machucado, seja na coluna, na cabeça ou no pescoço. Colocando os remédios bem ao lado dos nervos machucados, eles têm chance de melhorar mais rápido. Os três remédios que colocamos de rotina são: o anestésico local lidocaína, um remédio para a dor chamado clonidina e um tipo de corticóide chamado dexametasona.

\section{Detalhes sobre a existência de técnicas ou uso de remédios experimentais.}

2. Não tem procedimentos experimentais. O que o trabalho se propõe é realizar após uma vez apenas os bloqueios dos nervinhos neuropático e simpático, o tratamento direto com a radiofreqüência, que é um aparelho que manda através da agulha uma corrente iônica que vai adormecer os nervos machucados e deixar eles calmos. Este tratamento não é experimental, ele na verdade é utilizado há mais de 10 anos, porém a gente não tinha este aparelho aqui no Hospital das Clínicas. O tratamento com radiofreqüência não dói, é realizado igual aos outros bloqueios, no centro cirúrgico, onde a gente pode usar um aparelho chamado intensificador de imagem, que permite que a gente enxergue 0 paciente por dentro, e ache os nervinhos de uma forma bem precisa, para poder jogar o remédio ou a corrente da radiofreqüência direto neles.

\section{Descrição do tratamento dos participantes da pesquisa.}

3. Cada paciente vai receber os bloqueios indicados para tratar os dois tipos de nervinhos machucados, ou seja, bloqueio chamado neuropático, onde a gente coloca a combinação de clonidina, lidocaina e dexametasona direto ou nos nervos da coluna, ou nos nervinhos da dor do pescoço, ou nos nervinhos do rosto, depende do local da dor do paciente. Isto é feito de rotina há mais de 20 anos no nosso serviço de dor. Após, ao invés de repetir estes procedimentos mais 3 vezes, uma vez por semana, será realizado apenas uma vez o tratamento com a radiofreqüência. Vai ser feito para todos os procedimentos apenas um remedinho na veia para ficar mais tranquilo, uma combinação de midazolam com fintai. Durante a radiofreqüência, a gente vai 
Folha 3 de 3

Conversando com o paciente, que vai estar calmo e acordado, e vamos perguntando se está sentindo um choquinho no lugar da agulha, ou se está sentindo o músculo pular sozinho. Quando o paciente for fazer o bloqueio no pescoço, por causa de dor no braço e pescoço, a gente vai pedir também para o paciente falar "AAA", ou "EEE", ou "III", ou "OOO", só para ver se o nervinho que vai para a corda vocal, que é na verdade um músculo que ajuda a formar a voz no tom que a gente fala.

\section{Descrição do tratamento para quem desistir de participar da pesquisa ou se negar a participar da mesma.}

4. Quem desistir de participar da pesquisa não vai ser submetido a radiofreqüência, vai ser submetido ao tratamento atual, que é repetir todos os bloqueios dos nervinhos neuropático e simpático uma vez por semana, 4 semanas seguidas, e repetir tudo novamente a cada 4 meses. Quem for submetido á radiofreqüência vai fazer uma vez os bloqueios dos nervinhos neuropático e simpático, e após uma vez a radiofreqüência, e avaliar uma vez por mês, porém repetir bloqueio somente se necessário ao redor de uma no depois.

\section{Descrição de possíveis intercorrências da radiofrequência.}

5. As costas, pescoço ou cabeça não ficam anestesiadas com nenhum dos bloqueios ou radiofrequência. Não sente dor porque a gente usa remédio que desinflama (dexametasona) e que tira a dor do nervo (clonidina e lidocaina). Se ficar um pouco dolorido após a radiofrequência ou bloqueio, vai ser prescrito dipirona, 1 comprimido de $500 \mathrm{mg}$ a cada 6 horas, se necessário.

Descrição da previsão da dor nas costas, ou pescoço, ou cabeça

6. O que a gente espera é que a dor vá desaparecendo, e que o paciente possa diminuir o quanto toma de remédio para controlar a dor, que durma melhor, que consiga realizar atividades durante o dia, ou seja, que melhore a qualidade de vida.

\section{Gastos para participação na pesquisa.}

7. Não tem despesa para o paciente, porque os remédios do procedimento são utilizados de rotina no serviço de dor, não precisa comprar remédio. O responsável é o pesquisador responsável (Dra. Gabriela R Lauretti).

\section{Acompanhamento no Serviço de Dor.}

8. O acompanhamento é semanal, durante as primeiras 4 semanas, e depois mensal, por um ano. Porém, qualquer dúvida, pode ligar para meu telefone e eu resolvo: (16) 91766266.

Assinado (o paciente):

Assinado (Dra. Gabriela Rocha Lauretti)

Assinado (Dr. Carlos Alexandre de F. Trindade) 